\title{
Optimization, Power Management and Reliability Evaluation of Hybrid Wind-PV-Diesel-Battery System for Rural Electrification
}

\author{
Adel Yahiaoui ${ }^{1}$,, Abdelhalim Tlemçani ${ }^{1}$, Abdellah Kouzou ${ }^{2}$ \\ ${ }^{1}$ Electrical Engineering Department, Yahia Fares University, Medea, Algeria \\ ${ }^{2}$ Faculty of Science and Technology, Ziane Achour University, Djelfa, Algeria
}

Email address:

yahiaoui.industry@gmail.com (A. Yahiaoui)

${ }^{*}$ Corresponding author

\section{To cite this article:}

Adel Yahiaoui, Abdelhalim Tlemçani, Abdellah Kouzou. Optimization, Power Management and Reliability Evaluation of Hybrid Wind-PVDiesel-Battery System for Rural Electrification. Automation, Control and Intelligent Systems. Vol. 9, No. 3, 2021, pp. 73-88. doi: 10.11648/j.acis.20210903.11

Received: April 26, 2021; Accepted: May 11, 2021; Published: August 18, 2021

\begin{abstract}
Photovoltaic and wind energy are the most promising as a future energy technology and can be classified as a clean sources of electric energy in the world. Size optimization of the hybrid renewable energy system play an important role in minimizing the total cost of the system $\left(\mathrm{T}_{\mathrm{CS}}\right)$ and suitable load supply. The main focus of this research is to develop the efficient approach for the optimization of hybrid renewable energy system composed by photovoltaic area, wind turbine (WT), diesel generator (DG) and battery bank (BB). For this purpose, this paper proposes a new metaheuristic technique called modified grey wolf optimizer (M-GWO) for minimize the $\mathrm{T}_{\mathrm{CS}}$ of the hybrid system considering power balanced between the components. The study of reliability with loss power supply probability (LPSP), the energy not supplied (ENS) and the reliability of the power supply (RPS) methods are demonstrated. For improving the high exploration and exploitation to find the global optimum and robustness of our new approach the obtained results by M-GWO are compared with Grey Wolf Optimizer (GWO) and particle swarm optimization (PSO) methods.
\end{abstract}

Keywords: HPWDBS, LPSP, M-GWO, GWO, PSO

\section{Introduction}

Nowadays, the world global electrical energy demand is increasing day by day at an accelerating pace. Indeed, it is expected in the coming years that this demand cannot be entirely met by the conventional sources of energy due to their limited primary resources and fast depletion. However, there are important growing concerns caused by these sources, which are used mainly and abundantly in domestic, industrial and transportation applications, such as air pollution, greenhouse gas emissions and climate change all over the globe [1-3] Therefore, the actual tendency of the energy producer and consumer at all level, is to find new alternative sources mostly environmental friendly to overcome this gap such as renewable energy sources, which have been already exploited during the last two decades in ascendant manner [4,5]. At the end of 2019, the global electrical energy capacity generation reached $2537 \mathrm{GW}$ with an increase rate of $7.45 \%$ and $15.6 \%$ in respect to 2018 and 2017 respectively (which provided approximately $26.5 \%$ of the global electricity) [6].

In all countries of the world, electricity is more essential than ever for economic development. Its importance increases with technological developments, the population growth, the industrialization and the need for modern comfort. The increase in its production is therefore synonymous with an increase in the quality of life and the creation of wealth.

By 2016 approximately $18 \%$ of the global population living in developing countries especially in rural and underdeveloped areas locked access to electricity [7]. Indeed, the conventional energy sources such as natural gas, oil, coal and nuclear plants, even with their fast depletion, are still dominating the almost energy market demand. Unfortunately, all this energy sources has resulted in tremendous increases 
in $\mathrm{CO}_{2}$ emissions, which are the primary cause of global warming [8, 9]. The recent statistics and studies have confirmed that the atmospheric $\mathrm{CO}_{2}$ concentration has increased by approximately $40 \%$ compared with that at the beginning of the industrial revolution [10]. This crucial situation has forced the all partners such as energy producer, consumer researcher and industrial for other available alternative energy sources, which would satisfy the reduction of environment pollution imprint and energy supply sustainability [11]. In the last decades, renewable energy systems have been increasingly turned into a popular solution for supplying energy due to technological progressions and their many merits compared to the aforementioned conventional solution of energy $[12,13]$.

Currently, the renewable energies contribution in electricity generation all over the world reaches $30 \%$ of the electricity supply, hence reducing the discrepancy with electrical energy produced from the coal by $10 \%$ compared to 2019. According to the report presented by the international energy agency (IEA) on April 2020, it has been estimated that the demand for renewable energy increases on 2020 by nearly $1 \%$ based on the demand registered on 2019 , which presents the highest increase compared to all other available energy sources. In fact, the global electricity generation from renewable energy sources has grown up by almost 5\% during 2020 despite the downturn and setbacks related to their supply chains and constructions due the an expected crisis ofthe pandemic Covid-19. Even though, the global growth of renewable energy is slower on 2020 compared to 2019, but this is the case of the general tendency caused by the slowdown since 2016. It is worthy to mention that the electricity generation from hydropower continues to be the important renewable energy source in 2020 by about $60 \%$ of all global renewable electricity generation despite the fact that it is highly dependent on rain precipitation and temperature, the remaining $40 \%$ is mainly produced by solar energies, wind energy, bio-mass energy, geothermal energy and marine energy [1]. In the recent years, there have been much increasing interests in investing on the wind and solar energies among the other available sources of energy due to their easy accessibility and abundance along the year in nearly all the parts of the globe with a difference of dominance from one to another depending on the zones. However, the characteristics of electrical power produced from solar energy based on and wind generation systems are based on the weather condition over all the year. These two systems are considered to be very unreliable in themselves without available storage system with sufficient capacity such as the chemical, mechanical, magnetic and thermal technologies or back-up system such as conventional engine generators. On the other side, the renewable energy system reliability increases significantly when two different renewable energy sources at least are hybridized with the presence of convenient storage system. In the hybrid system based on wind and solar sources, the availability of one of the two sources with the support of the storage system can cover the power demand in the absence of the other source. Even in the worst case, sufficient storage system capacity is required to ensure the power demand long cloudy and non-windy days. Thus, a hybrid energy system has the following major advantages compared to a single source-based system [14].

In addition, the integration of PV system, wind turbine system and diesel generator with battery bank as a backup system can ensure more reliability, high power generation flexibility, reduction of the operational costs and less air pollution [15].

At present, the capital cost of installing units for renewable energy system is still expensive compared with diesel generators. In order to generate the power from renewable energy continuously following the required demand, there is need for back-up systems such battery storage or diesel generators. Therefore, a proper methodology is required in order to build a hybrid PV-Wind-Diesel-Battery system (HPWDBS) which fits the optimal operation mode to ensure the aforementioned features.

In fact, the optimization of the hybrid generation system plays an important role in minimizing the total annual cost under suitable load supply without interruption. In this context, various aspects of stand-alone hybrid power generation system optimization have been presented, applied and discussed in several previous works over the past year [16-18]. Whereas, the optimization techniques have proposed for sizing of the hybrid system components and predicting the renewable generator output under various operating conditions. F. Huneke et al. have been used the linear programming for economic optimization of off-grid energy systems [19]. T. Wanjekeche et al. have used the particle swarm optimization algorithm for multi-objective function to obtain the optimal sizing of hybrid stand-alone micro-grid system based on wind, PV and storage batteries to ensure the required power electricity demand for the specified location habitants and the water supply plant [20]. A. Khan et al. have proposed a Jaya algorithm for finding the optimum sizing of a PV-WT-Battery hybrid system to fulfill the consumer power demand and the at minimal cost [21]. X. Wang et al. have presented a methodology for designing a hybrid renewable energy system consists of solar, wind and diesel generator as a backup resource as well as battery storage, where a receding horizon optimization strategy has been used and applied to a single-family residential home [22]. Ramli et al. have evaluated the optimal sizing of the PV-WT-DieselBattery system via multi-objective self-adaptive differential evolution algorithm for city Yanbu, located in Saudi Arabia. Where the authors have considered the reliability of a hybrid microgrid system via loss of power supply probability (LPSP), the cost of electricity and the renewable factor (RF), $\mathrm{d}$ in three cases with an application ondifferent houses [23]. Chellali et al. have performed a techno economical study of a hybrid stand-alone system in two sites in Algeria with important potential of wind and solar energies in order to determine the feasibility of such systems, where the authors have used the HOMER software for solving their problem of optimization [24]. Billinton et al., and Kaldellis et al. have implemented particle swarm optimization (PSO) 
algorithmfor optimal sizing of stand-alone power systems byachievingcontinuous and reliable energy supply to the considered load $[25,26]$. Other researchers have used the Genetic algorithm to find optimal size of a Wind-PV-Battery system subject to reliability based on the loss power supply probability (LPSP). However, they have not considered compensation cost due to electricity shortage as well as $\mathrm{CO}_{2}$ emission. Tanrioven et al. have explained the optimal design of reliable hydrogen-based stand-alone Wind-PV generating system with considering component outage. However, the authors have not considered the existence of DG unit as back-up power [27].

In this paper an optimal sizing of WT-PV-DG-BB hybrid system using modified grey wolf optimization (M-GWO) algorithm is proposed to find the optimal configuration and minimizing the total cost of the system $\left(T_{C S}\right)$. This work introduces the optimal design of a new HPWDBS to avoid the investment cost increase. A power management technique and economic model is developed and applied on the designed optimal hybrid system. Indeed $\mathrm{M}-\mathrm{GWO}$ is an adequate and fast global optimization technique for solving complex problems when other techniques are unable to reach the optimal solution. This system is classified as a standalone mode, where it is studied under two different operation conditions. The first operation mode which is considered as scenario I, concerns one month in winter season (January). Whereas, the second operation mode considered as scenario II, is dedicated to one month in summer season (July). Furthermore, this study proposes a HPWDDBS reliability model which aims in incorporating the reliability in the optimal sizing problem. In order to assess the impacts of the different components of the system on the optimization, a sensitivity analysis is also accomplished. The obtained results by M-GWO are compared with GWO algorithm. All details about modeling of PV system, WT, DG and Battery bank will be provided in the next section.

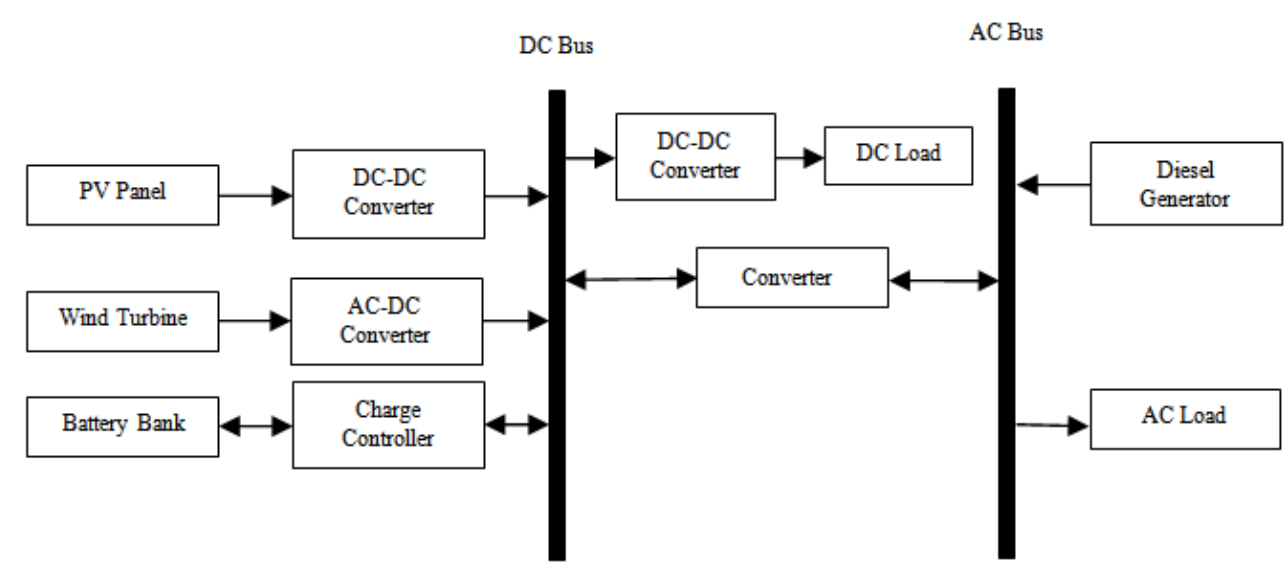

Figure 1. Hybrid WT-PV-DG-BB system configuration.

\section{Mathematical Model of HPWDBS}

In general, ahybrid PV-Wind- Diesel-Battery system (HPWDBS) consists of main four components such as the photovoltaic (PV) panels, the wind turbines, the diesel generators and thebatteries storage system. Furthermore, the proposed hybrid system requires two buses such as the DC bus and the $\mathrm{AC}$ bus to ensure the adaption of connectionof all these components and the expected loads. It is obvious that each component of this system and the eventual load are connected to the either DC bus or AC bus via power electronics converters. as illustrated in Figure 1., Indeed the photovoltaicpanels are connected to the DC bus via a DC-DC converter, the batteries storage systemareconnected to the DC busbar via a bidirectional DC-DC converter, the windturbineis connected to the DCbus via a AC-DC converter, the diesel generatorsand the residential loads are connected directlyto the AC busbar and finally the DC load is connected to the DC bus via a DC-DC converter. In the same time a DC-AC bidirectional converter is required to ensure the power exchange between the $\mathrm{DC}$ bus and the $\mathrm{AC}$ bus, it allows the transfer of power from the $\mathrm{AC}$ bus to the $\mathrm{DC}$ bus to ensure the charging of the batteries and powering the DC load in case of absence or insufficiency of the power produced from the PV system and the wind system. Moreover, if the produced power for the PV system and wind system exceeds the DC side demand, the excess of power will be transferred to the AC bus via the $\mathrm{DC}-\mathrm{AC}$ bidirectional converter to power the residential loads which means less power will be consumed from the AC generators, hence less cost is ensured. In this study a novel approach is proposed for optimizing the size of a hybrid renewable energy system for electrification of the city of Ghardaïa in Algeria. This basic architecture is used to test all possible configurations in order to determine the optimal dimensioning of the proposed hybrid system with an minimized cost and to fulfill the requirement of the load side demand.

\subsection{Photovoltaic System}

A PV panel can produce its peak power under standard conditions such as $1000 \mathrm{~W} / \mathrm{m}^{2}$ and $25^{\circ} \mathrm{C}$. However, in this study the effect of temperature is not taken into account in PV generation model. Hence, the output power of the PV panel is calculated as follows [28, 29]:

$$
\mathrm{P}_{\mathrm{PV}}=\mathrm{P}_{\mathrm{PV}, \mathrm{R}} * \eta_{\mathrm{PV}, \mathrm{MPPT}} * \mathrm{~S}_{\mathrm{P}} / 1000
$$


Where $\mathrm{P}_{\mathrm{PV}, \mathrm{R}}$ is the rated power of each photovoltaic panel, $\eta_{\mathrm{PV}, \mathrm{MPPT}}$ is the photovoltaic tracking efficiency and $\mathrm{S}_{\mathrm{P}}$ is the effective component of solar radiation. The number of 1000 is related to the standard radiation value.

\subsection{Wind Turbine System}

Wind turbine converts the kinetic energy of the wind into electric energy. It is well knownthat when the wind speed exceeds the cut-in value, the wind turbine generator begins turning and generating electrical power. If the wind speed reaches the rated speed of the wind turbine, it generates constant power and the pitch angle control intervenes in this case. If the wind speed exceeds the cutout value, the wind turbine generator has to be stopped to protect it. The expression of the instantaneous produced power of each wind turbine $\left(\varepsilon_{P_{W T}}\right)$ is function of the wind speed and it is defined as follows [30]:

$$
P_{W T}= \begin{cases}0 v(t) \leq v_{\text {cut-in }} \quad \text { or } \quad v(t) \geq v_{\text {cut-out }} \\ p_{r} \frac{v(t)-v_{\text {cut }- \text { in }}}{v_{r}-v_{\text {cut-in }}} & v_{\text {cut-in }}<v(t)<v_{r} \\ p_{r} & v_{r}<v(t)<v_{\text {cut }- \text { out }}\end{cases}
$$

Where $v$ is the wind speed, $\operatorname{Pr}$ is the rated power of the wind turbine, and $v_{c u t-i n}, v_{c u t-o u t}$, and $v_{r}$ are the cut-in, cut-out, and rated speed of the wind turbine, respectively. If the number of wind turbines is $\mathrm{N}_{\mathrm{WT}}$, the overall produced power from the wind turbine system is [31]:

$$
P_{W T}(t)=N_{W T} \times \varepsilon_{P_{W T}}(t)
$$

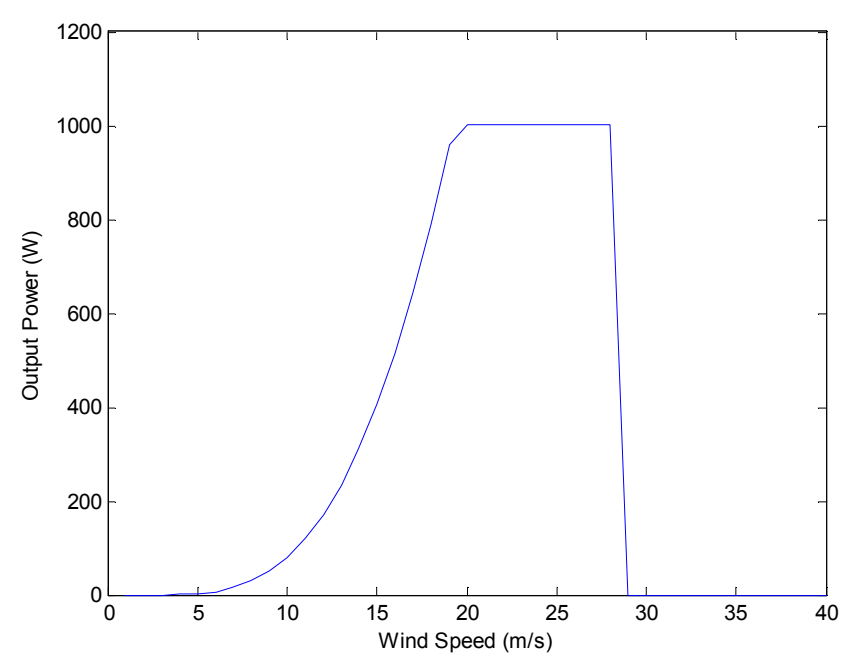

Figure 2. Power curve of $1 k W_{P}$ wind turbine.

\subsection{Diesel Generator System}

The diesel generator must be controlled to maintain the frequency and voltage of the system at the AC bus of the hybrid system which is supposed to be operating while the power system is running in stand-alone mode. Indeed, the diesel generator is composed of a diesel combustion engine driving a synchronous electrical generator which should be controlled to run at a constant speed to guarantee a constant frequency of its generated output voltage. It can supply the power demand up to a rated power under reliable and simple operation compared to other sources. It is considered as a backup source of power to the whole hybrid system where it begins operating and generating power when the produced power by other sources is not sufficient and the batteries storage system needs to be charged. It is obvious that the generated power from the diesel generator is a function of the fuel consumption $\mathrm{F}_{\mathrm{C}}$ (liter/hour), this function can be defined as follows $[30,31]$ :

$$
F_{C}=A \times P_{R}+B \times P_{D G}
$$

Where, $P_{R}$ is rated power of diesel generators, $P_{D G}$ is the output power of the diesel generators, $A=0.0845$ (liter $/ \mathrm{kWh}$ ) and $\mathrm{B}=0.246 \quad($ liter $/ \mathrm{kWh})$ are the coefficients of the consumption curve. The hourly cost of the fuel consumption can be obtained based on the fuel price which can be calculated based on the following expression [31, 32]:

$$
C_{f}=P_{\text {fuel }} \times F_{C}
$$

Where, $P_{\text {fuel }}$, is the fuel price.

\subsection{Storage System}

The batteries are frequently used in hybrid renewable energy system as the storage system. The quantity of electric charge and discharge is not only depending on the load demand but also on the state of charge (SOC). The SOC of the battery storage at the simulation time $t$ is obtained by equation (6) [33]:

$$
\operatorname{SOC}(t+1)=\operatorname{SOC}(t)+\frac{P_{b a t}(t) \times \Delta t}{N_{b a t} \times C_{b a t} \times V_{b a t}} \times \eta_{b a t}
$$

Where, $\mathrm{P}_{\mathrm{bat}}(\mathrm{t})$ is the input/output power (positive during charging and negative during discharging) of batteries. $\Delta \mathrm{t}$ is each simulation time step that is assumed to be an hour. The round-trip efficiency $\eta_{\text {bat }}$ is defined as $80 \%$ for charging and $100 \%$ for discharging models. Additionally, $\mathrm{N}_{\text {bat }}, \mathrm{C}_{\text {bat }}$ and $\mathrm{V}_{\text {bat }}$ denote the number of batteries, the nominal capacity and the nominal voltage of each battery, respectively.

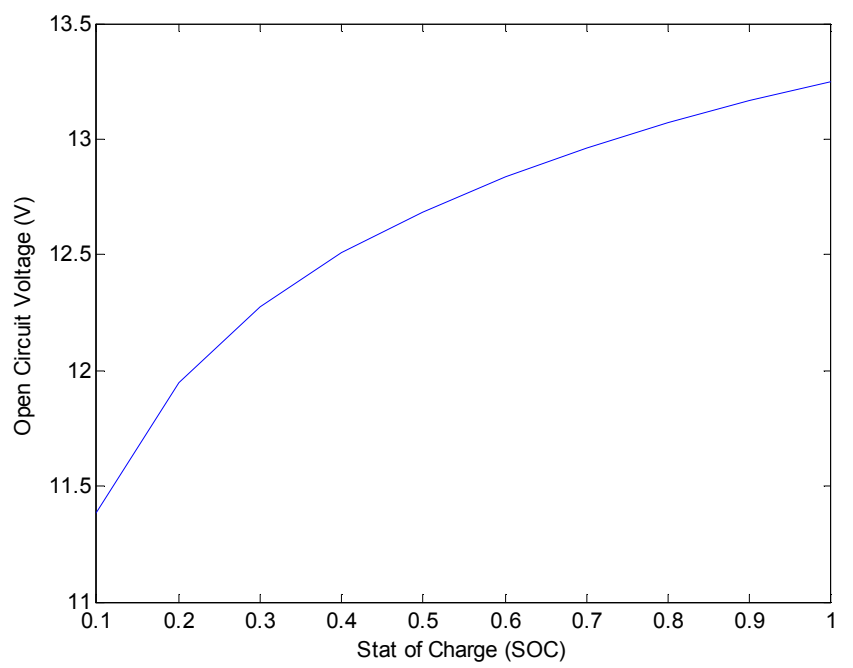

Figure 3. Voltage variation in charging mode depending on the state of charge. 
The battery model retains the SOC between the lower limit $\left(\mathrm{SOC}_{\min }\right)$ and the upper limit $\left(\mathrm{SOC}_{\max }\right)$ to ensure safety. The charge and discharge mechanism of battery banks depends on the condition of generated power in the hybrid system. Due to intermittent power from PV panels and/or wind turbines, power from battery bank is required whenever these two sources are unable to supply the sufficient power required by the load demand. Whereas, ifthe power produced from these two sources exceeds the load demand power, the excess power will be stored in the batteries storage system. On the other side, if this excess power is not sufficient for charging the batteries, the diesel generators can sustain the operation of the batteries charging. The variation of the open circuit voltage as a function of the state of charge (SOC) is shown in Figure 3.

\subsection{Converter}

A power electronicsconverter is a device that converts electric energy from one nature to another and vice-versa such asdirect current (DC) andalternative current (AC), where the voltage in the $\mathrm{DC}$ case and the voltage and the frequency in the AC case can be controlled. The process carried out in the converter is called inversion. It is important to know the relation between the power in the inverter and the incoming power. Since the load is supplied with alternating current, an inverter is therefore present between the direct bus and the load. There are various formulas, which defined the efficiency of an inverter based on the output power. The efficiency model is presented by the following empirical expression:

$$
\eta_{\text {inv }}=a \times(1-\exp (b \times \tau)
$$

Where, $\mathrm{a}$ and $\mathrm{b}$ are constants, $\tau$ is the load rate given by the relation:

$$
\tau=\frac{P_{S}}{P_{n}}
$$

Where, $P_{s}$ et $P_{n}$ represent the output power and the rated power of the inverter respectively. The variation of the inverter efficiency function of the load is represented in Figure 4.

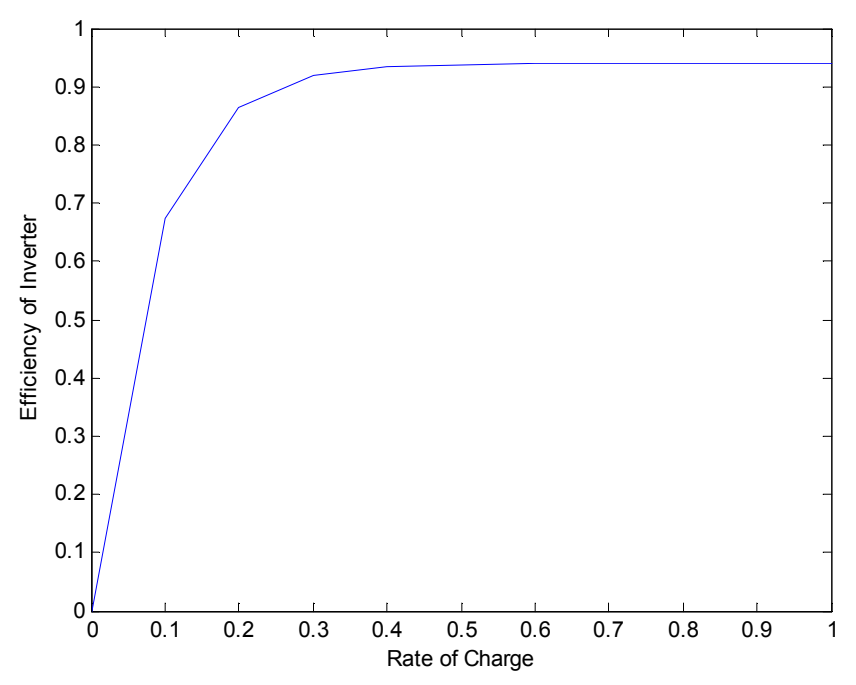

Figure 4. Inverter efficiency.

\section{Modeling of System Reliability}

Recently, to ensure the optimizing sizing of a hybrid power generation systems which is expected to fulfill the required power a load demand, some technical reliability approaches are used in some previous work. Among these employed techniques, trade-off method by [34], the least square method used by $[35,36]$ loss of power supply probability (LPSP) by $[35,37]$. In this study, loss of power supply probability (LPSP), energy not supplied (ENS), and reliability of power supply (RPS) are applied to evaluate the reliability of the HPWDBS. The methodology used in this work can be summarized in the following steps:

The power generated by hybrid system at time $t$ can be expressed by the following equation:

$$
P_{G}(t)=P_{W T}(t)+P_{P V}(t)+P_{D G}(t)
$$

It is well obvious that the reliability is the main concern to be ensured within any feasible HRES. It is used to evaluate the dynamics of the concerned power sources in fulfilling the power demand requirements following the nature of load. It can be defined in term of LPSP which is determined based onstatistical data, it allows indicating if the generated power cannot success in fulfilling the load demand either due to technical raisons orfailure of renewable energy sources in producing the required power. It can be summarized as follows:

If LPSP $=0$, the mean generated power supplyfulfills the required load demand.

If LPSP $=1$, the mean of the required load demand is not ensured by the generated power.

The LPSP analysis can be evaluated based on probabilistic methodology and chronological simulation [38, 39]. It presents the fraction of the unsatisfied demand on that demanded by the load; it expresses the rate of nonsatisfaction of the load. Thus, this probability is defined the ratio between the sum of the energy not supplied 'ENS' and the total energy demanded by the load during a period of operation, as follows [18]:

$$
L P S P=\frac{E N S}{\sum_{t=0}^{T} P_{L}}
$$

The energy not supplied (ENS) can be obtained by following equation:

$$
E N S=\sum_{t=0}^{T}\left(P_{L}-P_{P V}-P_{W T}-P_{D G}\right)
$$

Where; $P_{L}$ is the total energy demanded by the load. On the other side, the reliability of the power supply (RPS) can be defined as follows:

$$
R P S=1-L P S P
$$

\section{Optimization Problem Formulation}

This paper proposes the application of the grey wolf optimization (GWO) algorithm for finding the optimal design of Wind-PV-Diesel-Battery hybrid system used in an isolated area. The GWO is used to minimize the objective function proposed in this work which is 
dedicated for ensuring an optimal sizing of the studied hybrid system. The proposed objective function aims in minimizing the total cost of the system $\left(\mathrm{T}_{\mathrm{CS}}\right)$. It can be calculated based on the total capital cost $\left(\mathrm{T}_{\mathrm{CC}}\right)$, the total fuel cost $\left(\mathrm{T}_{\mathrm{FC}}\right)$ of diesel generators, the total replacement cost $\left(T_{R C}\right)$, the total maintenance cost $\left(T_{M C}\right)$ and the total emission cost $\left(\mathrm{T}_{\mathrm{EC}}\right)$ produced by diesel generators. The case study presented in this paper is taken from southern Algeria (Ghardaïa).

\subsection{Objective Function}

The objective function of optimization problem of the studied hybrid system is defined as follows [40]:

$$
\min T_{C S}\left(N_{P V}, N_{W T}, N_{D G}, N_{B B}=\sum_{i=P V, W T, D G, B B} T_{C S_{i}}\right.
$$

Where,

$$
T C S=T_{C C}+T_{R C}+T_{M C}+T_{E C}-S
$$

$T_{C C}$ of the HPWDBS can be calculated by:

$$
\begin{array}{r}
T_{C C}=\left(C_{P V} \times N_{P V}+C_{W T} \times N_{W T}+C_{D G} \times N_{D G}+C_{B B} \times\right. \\
\left.N_{B B}\right) \times C R F
\end{array}
$$

Where, $C_{P V}, C_{W T}, C_{D G}$ and $C_{B B}$ presents the capital cost in $\$$ of PV panel, wind turbine, diesel generator and battery bank respectively. CRF is capital recovery factor, a ratio to calculate thepresent value of a series of equal annual cash flows which can be calculated as follows [41]:

$$
C R F=\frac{i(1+i)^{y}}{(1+i)^{y-1}}
$$

Where, y denote the lifetime of the system and iis the interest rate.

In this work, the units that need replacement are the wind turbine and the battery bank. Hence, the $T_{R C}$ can be calculated from the following equation [41]:

$$
T_{R C}=C_{R P} . S F F\left(i, y_{R P}\right)
$$

Where, $C_{R P}$ is the replacement cost of battery banks and wind turbines in $\$, y_{R P}$ is the annual lifetime of the battery banks and the wind turbines. $S F F$ is the sinking fund factor, a ratio to calculate the future value of a series of equal annual cash flows. This factor iscalculated as follows (Yang et al., 2008):

$$
S F F=\frac{i}{(1+i)^{y-1}}
$$

The total maintenance cost of the system can be obtained by the following equation:

$$
T_{M C}=C_{C a p}(1-\lambda) / y
$$

Where, $C_{\text {Cap }}$ is the capital cost of components and $\lambda$ is the reliability of components.

The $C_{O 2}$ emission produced by the DG under operation needs to be treated in order to prevent atmospheric pollution. It can be evaluated based on the $T_{E C}$ which is expressed as follows [42]:

$$
T_{E C}=\sum_{t=1}^{T} E_{f} \cdot E_{c f} \cdot P_{D G}(t) / 1000
$$

Where, $E_{f}$ is emission factor and $E_{c f}$ is the emission cost factorwhich has a value between US\$30/Ton and US\$50/Ton [42].

$\mathrm{S}$ is salvage value of hybrid system. Salvage values of each system unit was given by equation (21). Where $\delta_{i}$ is salvage value of each system component $\left(\$ / \mathrm{m}^{2}\right), \gamma$ is inflation rate and $N_{i}$ is size estimated by during optimization $\left(\mathrm{m}^{2}\right)$ :

$$
S=\delta_{i} \cdot N_{i} \cdot\left(\frac{1+\gamma}{1+i}\right)^{N}
$$

\subsection{Constraints}

The fitness function defined by equations (13) which its minimum value leads to the minimization of the size of HPWDBS system components in order to meet the desired power load demand, and hence the minimum of the total cost can be obtained minimize the total cost of the system. In the present work Here the following constraints conditions have to be taken into account consider through the whole process of optimization such as the number of PV panels $\left(N_{P V}\right)$, the number of the wind turbines $\left(N_{W T}\right)$, the number of the diesel generator $\left(N_{D G}\right)$ and the number of the battery bank $\left(N_{B B}\right)$, which have to be within the following ranges:

$$
\begin{aligned}
& 0<N_{P V} \leq P_{P V \max } \\
& 0<N_{W T} \leq P_{W \max } \\
& 0<N_{D G} \leq P_{D G \max } \\
& 0<N_{B B} \leq P_{B \text { Bmax }}
\end{aligned}
$$

It is necessary to mention that the diesel generators (DGs) cannot operate under their minimum setting and above its nominal capacity.

$$
P_{D G \min } \leq P_{D G} \leq P_{D G \max }
$$

The value of the capacity of batteries must be greater than the minimum energy level available in the battery banks, and it cannot be greater than the maximum energy level during the charging of the batteries.

$$
C_{B B \min } \leq C_{B B} \leq C_{B B \max }
$$

In order to consider the reliability of the system, the loss of power supply probability (LPSP) should be less than the maximum settled LPSP of the user:

$$
L P S P \leq L P S P_{\max }
$$

\section{Grey Wolf Optimizer (GWO) Algorithm}

The Very recent meta-heuristic optimization Grey wolf optimization (GWO) algorithm inspired by gray wolves has been is developed and proposed by Mirjalili et al, it is inspired from The GWO algorithm imitates the hunting and the social hierarchy behaviors of grey wolves. Indeed, in add it into the advantages of meta-heuristic algorithms; this algorithm 
requires no specific input parameters to be initialized which presents and advantage compare to their meat-heuristic algorithms counterparts. The social dominant hierarchy of the grey wolves is employed with the help of alpha $(\alpha)$, beta $(\beta)$, delta $(\delta)$ andomega $(\omega)$ wolves as shown in Figure 5 where alpha $(\alpha)$ wolf is the wolf leader [43].

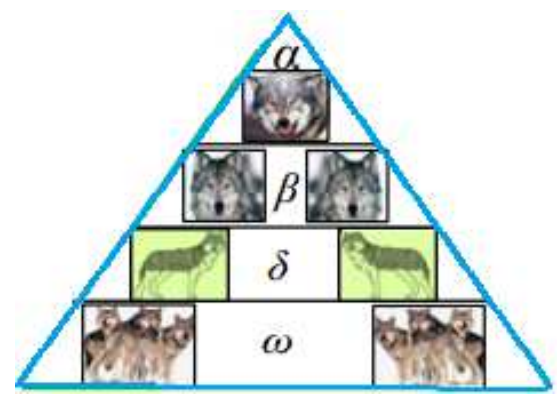

Figure 5. The main types of gray wolves

The following equations (22) and (23) have been suggested were suggested for modeling the prey for encircling prey and hunting mechanism of grey wolves [43]:

$$
\begin{gathered}
\vec{D}=\left|\vec{C} \cdot \overrightarrow{X_{p}}(t)-\vec{X}(t)\right| \\
\overrightarrow{X(t+1)}=\overrightarrow{X_{p}}(t)-\vec{A} \cdot \vec{D}
\end{gathered}
$$

Where $\vec{X}$ presents the position vector of grey wolf, $\overrightarrow{X_{p}}$ presents the position vector of prey, $\mathrm{t}$ presents the current iteration, and $\vec{A}, \vec{C}$ are coefficient vectors which can be calculated as given in equations (24) and (25):

$$
\begin{gathered}
\vec{A}=2 \vec{a} \cdot \overrightarrow{r_{1}}-\vec{a} \\
\vec{C}=2 \overrightarrow{r_{2}}
\end{gathered}
$$

Wherein $\overrightarrow{r_{1}}$ and $\overrightarrow{r_{2}}$ are irregular vectors between 0 and 1 , and $\vec{a}$ isa vector taking the decreasing value from 2 to 0 during the process ofiterations.

The grey wolves can recognize the location of prey and it will be guided by alpha wolve to be encircled. However, the position of the optimum prey is not known in search space. The mathematical model of the hunting behavior of grey wolves can be described as; alpha, beta, and delta and they represented the wolves that have more information about the potential position of prey. So, the first three best solutions are saved and others such as omegas should revise their positions for better than current ones as described the following equation (26) to (32):

$$
\begin{aligned}
& \vec{D} \alpha=\left|\overrightarrow{C_{1}} \cdot \vec{X} \alpha-\vec{X}\right| \\
& \vec{D} \beta=\left|\overrightarrow{C_{2}} \cdot \vec{X} \beta-\vec{X}\right| \\
& \vec{D} \delta=\left|\overrightarrow{C_{3}} \cdot \vec{X} \delta-\vec{X}\right| \\
& \vec{X} 1=\vec{X} \alpha-\vec{A} 1 \cdot \vec{D} \alpha \\
& \vec{X} 2=\vec{X} \beta-\vec{A} 1 \cdot \vec{D} \beta \\
& \vec{X} 3=\vec{X} \delta-\vec{A} 1 \cdot \vec{D} \delta
\end{aligned}
$$

$$
\vec{X}(t+1)=\frac{\vec{X} 1+\vec{X} 2+\vec{X} 3}{3}
$$

When the prey stops moving, grey wolves finish the hunting. To explain this implementation mathematically, value of $\vec{a}$ is decreased from 2 to 0 ; hence, $\vec{A}$ is decreased also as described in equation (24). When the values of $\vec{A}$ are between -1 and 1 , grey wolves attack to prey. Another value of GWO is $\vec{C}$ which varies between 0 and 2 , it changes its weights value for the prey in order to stochastically emphasize $(\vec{C}>1)$ or deemphasize $(\vec{C}<1)$ the effect of the prey in defining the distance. This component is useful for rescuing of solution from local optima, particularly in the last iteration. The GWO algorithm is terminated by satisfying a final criterion.

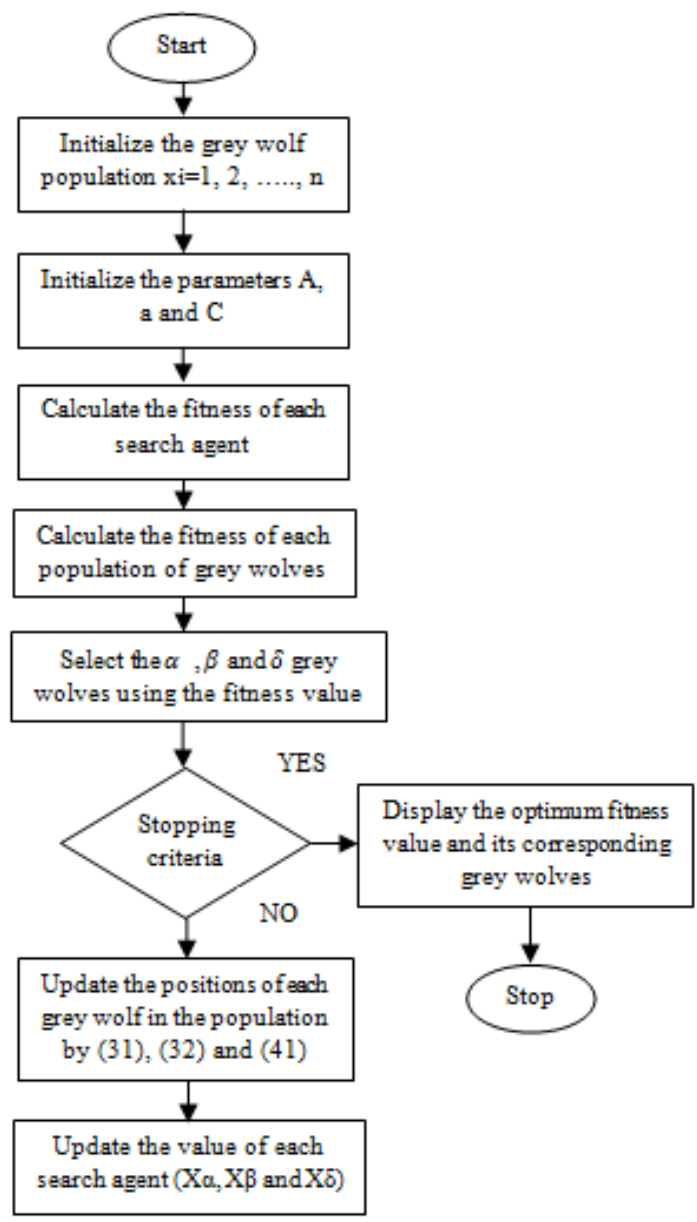

Figure 6. Flowchart of $M-G W O$ algorithm.

\section{Modified Grey Wolf Optimizer (M-GWO) Algorithm}

The most difficult task in all optimization techniques is to find the overall minimum. Although various improvements toalgorithms favor the avoidance of local optima, the literature shows that population-based algorithms are better at handling this problem. Regard less of the differences between population based algorithms; the common point is the division of the optimization process into two conflicting 
stages which are exploration versus exploitation. In the method of optimization by GWO we can find the global minimum with a very good speed of convergence by adjusting on the parameters a and A. Exploration and exploitation are two parameters which are inversely proportional, one leading to the degradation of the other. A balance adjustment between these two parameters can guarantee a very precise approximation of the overall optimum. Trop d'exploration est similaire à trop de hasard et ne donnera probablement pas de bons résultats d'optimisation. Mais trop d'exploitation est liée à trop peu d'aléatoire. Par conséquent, il doit y avoir un équilibre entre exploration et exploitation.

In GWO, the value of $a$ decreases linearly from 2 to 0 using the update equation as follows:

$$
a=2\left(1-\frac{i}{N}\right)
$$

Where, $\mathrm{N}$ indicates the maximum number of iterations and $i$ is the current iteration. Our M-GWO employs exponentialfunction for the decay of $a$ over the course of iterations. Consider following equation:

$$
a=2\left(1-\frac{i^{2}}{N^{2}}\right)
$$

The flowchart of M-GWO process is depicted in Figure 6.

\section{Implementation of M-GWO Algorithm in HPWDBS}

The implementation of the optimization algorithm of finding the optimal sizing of the studied hybrid system has been performed off-line using $\mathrm{m}$-file on Matlab software. The M-GWO is used to find the optimal configuration of the system under study, southern part in Algeria. The flowchart of the optimization process is based on yearly meteorological data, load profile, specification of units andfurther data that areused for economic and reliability evaluation. For the implementation of the $\mathrm{M}-\mathrm{GWO}$ in solving the problem of sizing optimization of difference source components of the proposed hybrid systems such as Wind-PV-Diesel generatorBattery bank system, the following steps have been applied:

Initialization the population and the parameters of $\mathrm{M}$ GWO.

Initialization the search agent and generation of the chosen variables randomly, in the present case there are 4 vectors which represent the size of Wind turbines, PV panels, battery banks and diesel generators.

Calculation of the objective function according to equation (13) of each search agent.

Selection of the best search agent corresponding to the lowest objective function value.

Update the search agent position by equation (32), while $\mathrm{t}<$ max number of iterations and determine the number of wind turbines $\left(\mathrm{N}_{\mathrm{WT}}\right)$, PV panels $\left(\mathrm{N}_{\mathrm{PV}}\right)$, number of battery banks $\left(\mathrm{N}_{\mathrm{BAT}}\right)$ and number of diesel generators $\left(\mathrm{N}_{\mathrm{DG}}\right)$.

Calculation of the objective function based on each new search agents.

Find the new best search agent and replace it with the old best search agent, otherwise the new is better than the old best search agent.

This cycle is terminated if the stopping criterion is met.

After terminating the cycle, the best of all considered solutions will be returned.

Simplified flow chart of the optimization process is shown in Figure 7. During the optimization, variables such as radiation, air temperature, wind speed, load data, and parameter of equipment were used as input. After that, decision variables such as $N_{P V}, N_{W T}, N_{D G}$ and $N_{B B}$ were estimated by M-GWO for each iteration. Then, power of PV panel, power of WT and power of DG were calculated with variable inputs, constant inputs. In order to meet the load, it was considered that the generated energy was supplied primarily from PV and WT during the decision-making process. If the power product by PV panel and wind energy were insufficient, BB energy was considered as a back-up generator. If the power produced by PV panel, WT and BB was not sufficient to supply the load demand, DG energy was considered a back-up generator of the system. During optimization, LPSP values were calculated for $744 \mathrm{~h}$, and if the LPSP value was above the set value, the decision variables were returned. If LPSP was desired value, the optimization process was performed.

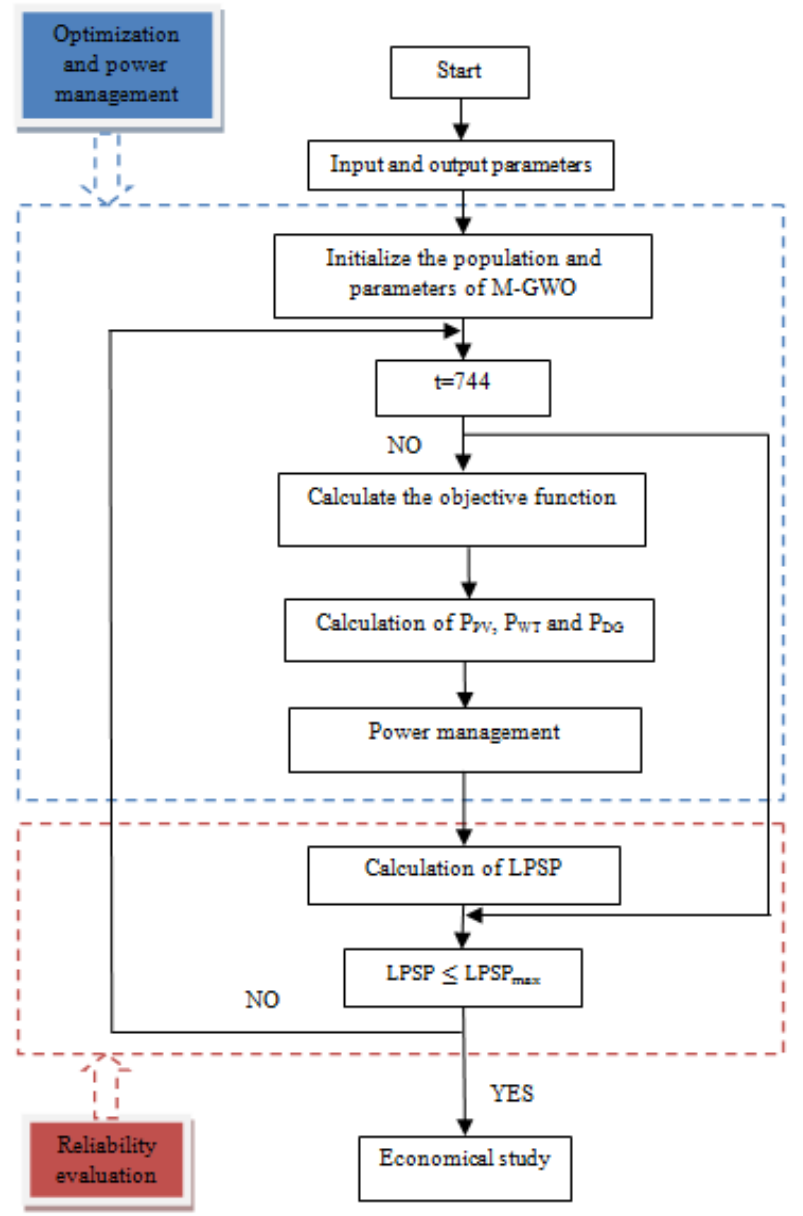

Figure 7. Flow chart of optimization by M-GWO. 
In this study, the number of search agent and maximum number of iteration are considered as 30 and 100 , respectively.

\section{The Case of Ghardaïa City}

In this work, we are providing electricity to a small isolated village (not connected to the grid), thanks to the use of a hybrid system for the production of energy in the wilaya of Ghardaïa. Based on real data (temperature, solar radiation and wind speed), a two-month study carried out in January (winter) and July (summer), for the total energy consumed with the use of the autonomous hybrid system, including solar panels (PV), wind turbines (WT), diesel generators (DG), batteries and converters.

\subsection{Location}

The city of Ghardaïa is located north of the Algerian desert, $600 \mathrm{~km}$ south of Algiers, with a total estimated area of $86105 \mathrm{~km}^{2}$, from north to south $450 \mathrm{~km}$, from east to west of 200 to $250 \mathrm{~km}$ from sea level to 486 meters.

\subsection{The Climate}

The desert climate is dry; the temperature is wide between day and night and between winter and summer, between 1 and 25 degrees in winter and between 18 and 48 degrees in summer. The air is temperate in the spring and fall and the skies are clear most days of the year.

\subsection{Site Coordinates}

Latitude: $32.38^{\circ} \mathrm{N}$

Longitude: $3.82^{\circ} \mathrm{E}$

Altitude: $450 \mathrm{~m}$

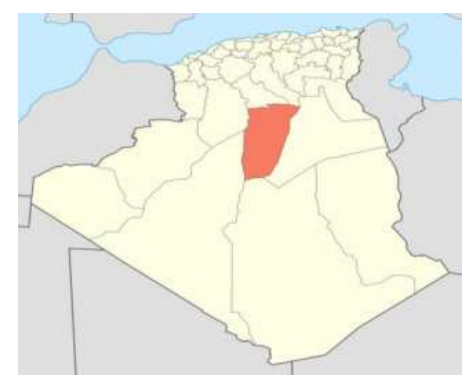

Figure 8. Location of Ghardaia city in Algeria.

\section{Simulation, Results and Discussion}

This paper introduces the design of the hybrid power system, which consists of WT, PV, DG, and BB for electrification of rural city in Algeria. Modern meta-heuristic technique called modified grey wolf optimizer (M-GWO) has been applied to find the optimal design of the proposed hybrid power system. This system is designed at two different scenarios; summer and winter to consider all weather conditions. Figure 9 shows the hourly load profile for months of January and July from Ghardaïa. We calculate the amount of electricity needed to cover the electrical needs of the village, with a thorough study of all the electrical instruments used, which is represented by the amount of electricity consumed, and the hours of operation through 24 hours (day by day and hour by hour). The load profile consists of 20 homes, school, clinic and public lighting, taking into account the frequency of electrical devices during their operation under a standard voltage $230 \mathrm{~V}-50 \mathrm{HZ}$.

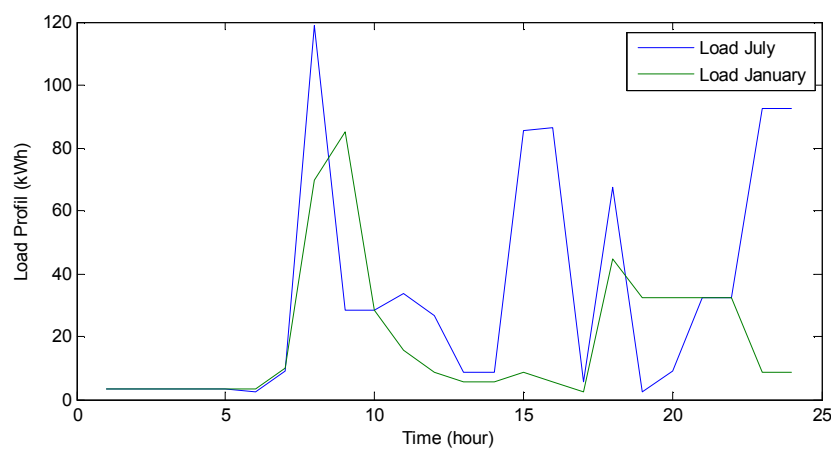

Figure 9. Hourly electric load variation of two seasons.

Solar radiation and ambient temperature are the two parameters with the most profound effects on the output PV power. The output power of PV panel is presented in Figure 10. The solar radiation and ambient temperature data are detailed as follows:

Figure 11 shows the data of solar radiation; we got the hourly insolation data for the months of January and July. We note that the irradiation values for January range from 0 to $710\left(\mathrm{~W} / \mathrm{m}^{2}\right)$ and 0 to 1028 for July.

Figure 12 shows the data of ambient temperature from the region of Ghardaïa, in the same way, the hourly values of the temperature is varied between day and night, it varies between 4 and $25^{\circ} \mathrm{C}$ for month of January, and 25 to $47^{\circ} \mathrm{C}$ for month of July.

Wind measured data has been used with the information of height $10 \mathrm{~m}$. Figure 13 shows the hourly values for the month of January and July of wind speed from the region of Ghardaïa. The wind speed is varied between $0.44 \mathrm{~m} / \mathrm{s}$ to 17 $\mathrm{m} / \mathrm{s}$ and $0.36 \mathrm{~m} / \mathrm{s}$ to $15.72 \mathrm{~m} /$ srespectively.

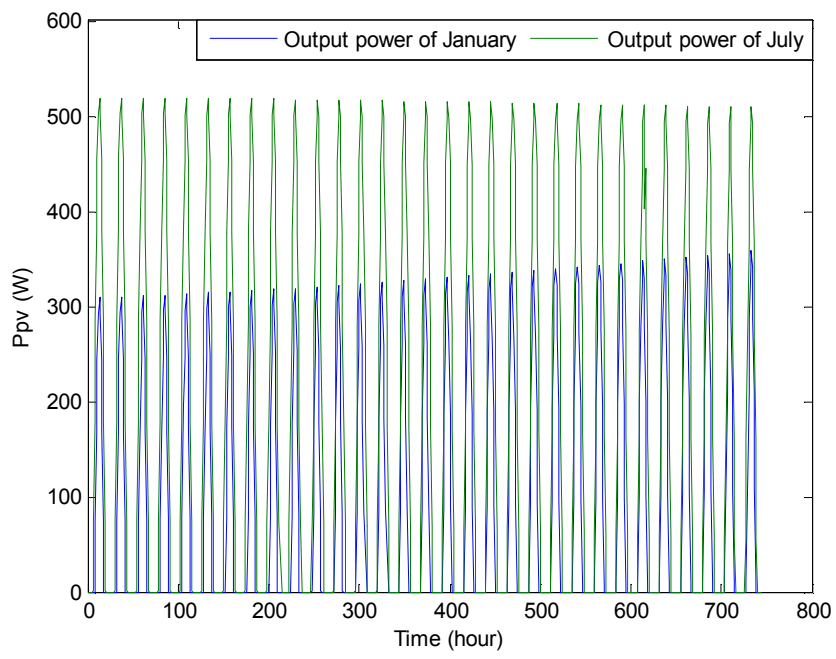

Figure 10. Hourly power generated by PV panel. 


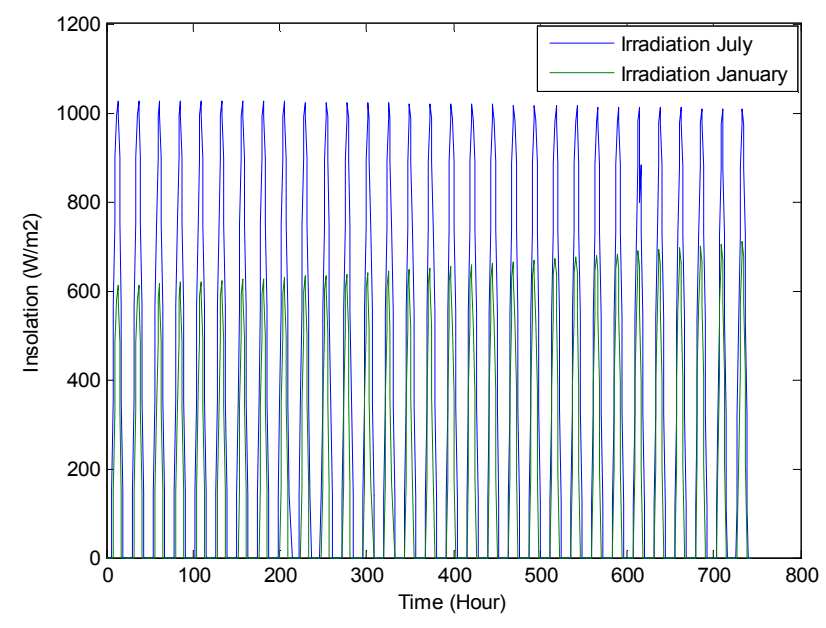

Figure 11. Hourly variation of solar radiation.

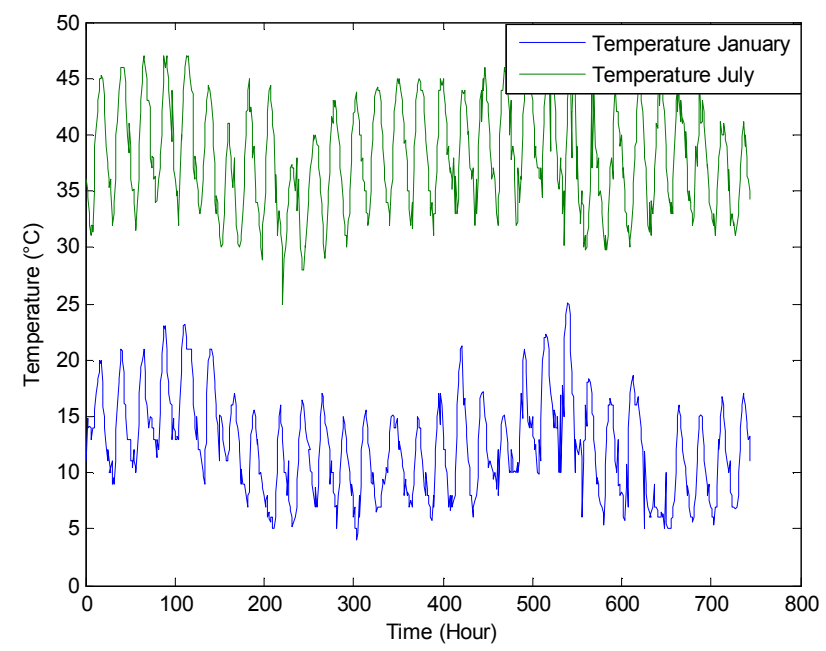

Figure 12. Hourly temperature variation.

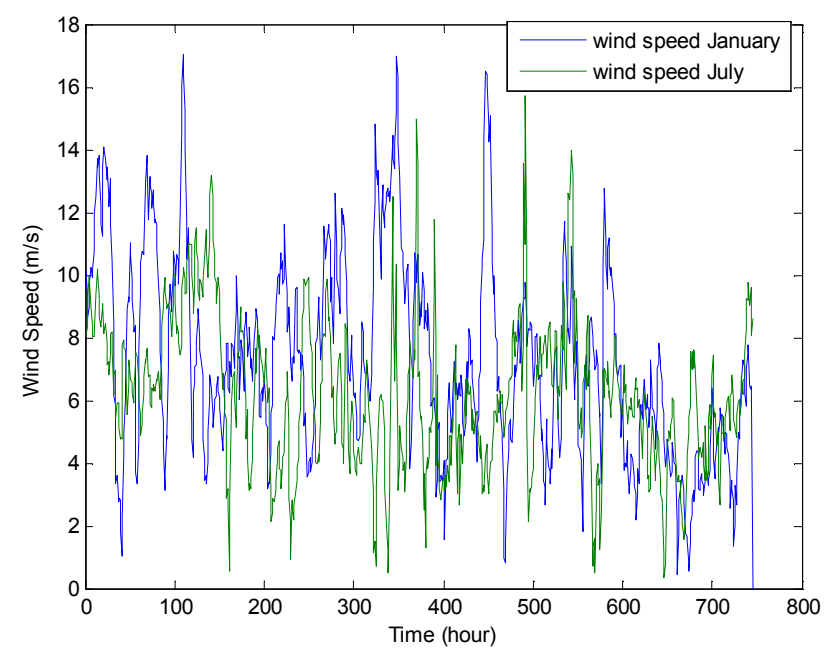

Figure 13. Hourly wind speed variation.

Figure 14 shows the graphs of the powers produced by thewind generator.

The load demand is supplied from PV panels, wind turbines, diesel generators and batteries. The values of design parameters applied in optimization problem are presented in table 1 . The life of WT and BB are 10 years, 5 years respectively. The results of system optimization for month of January obtained by M-GWO technique compared to GWO and PSO are presented in table 2. It can be seen that the proposed system consists of 4 units of WTs, $60 \mathrm{PV}$ panels, $2 \mathrm{DG}_{\mathrm{s}}$ and 93 units of battery banks to guarantee the system work successfully. The inverter size is taken according to the maximum power from PV panel, WTs, $\mathrm{DG}_{\mathrm{s}}$ and $\mathrm{BB}_{\mathrm{s}}$. The results show that the optimal solution using M-GWO leads to cost 593296,701 \$. While the cost of implementing GWO and PSO for month of January are $593557,896 \$$ and 593835,290 \$ respectively. The optimal solutions by M-GWO for month of July presented in table 3 are 3 units of WTs, $61 \mathrm{PV}$ panels, $9 \mathrm{DG}_{\mathrm{s}}$ and 68 units of battery banks. The $\mathrm{T}_{\mathrm{CS}}$ value in M-GWO $(592937,923 \$$ ) is lower in comparison with GWO (594170,647 \$) and PSO (594291,194 $\$$ ). The proposed method has the lowest cost. So, it can be said the proposed method is better than other methods. Also, after different simulations obtained in table 2 and table 3 we can be seen that the values of LPSP and ENS are increased, while RPS is decreased. So, it can be concluded that the availability of HPWDB plays a key role on system optimal sizing and accurate design of system power generation. In these simulations MGWO parameters consists of 30 search agent and 100 iterations. The convergence curves of M-GWO algorithm compared to GWO and PSO for month of January and July are depicted in Figure 15 and Figure 16 respectively. Moreover, the optimal configuration obtained by our approach is able to satisfy the load demand without unmet load during simulation process.

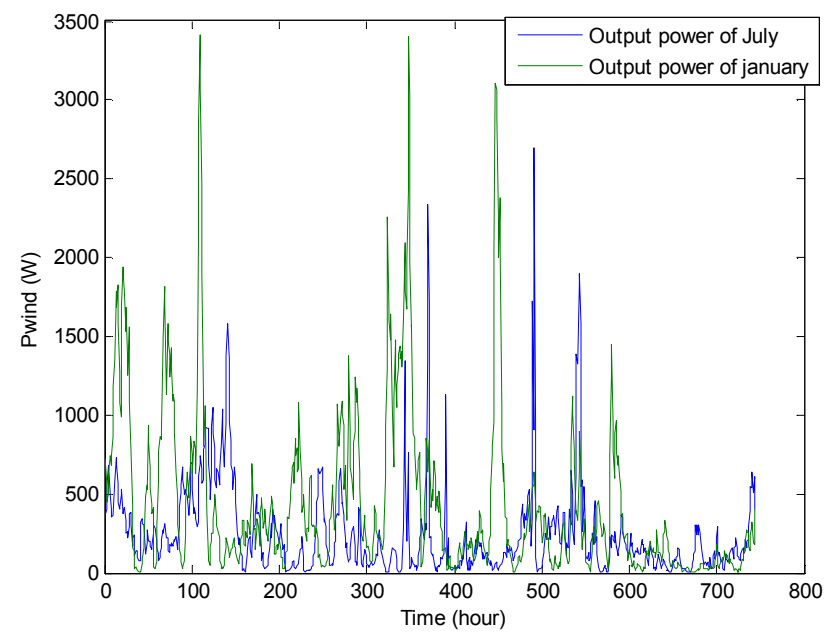

Figure 14. Produced power from wind turbine.

Table 1. Design parameter considered for HPWDBS optimization.

\begin{tabular}{ll}
\hline Parameters & Values \\
\hline System life time (years) & 20 \\
PV panels life time (years) & 20 \\
Battery banks life time (years) & 5 \\
Inverter life (years) & 20 \\
Wind turbine life time (years) & 10 \\
Power of PV panel $(\mathrm{W})$ & 360 \\
Power of wind turbine $(\mathrm{kW})$ & 1 \\
Power of diesel generator $(\mathrm{kW})$ & 3 \\
Rated battery capacity $(\mathrm{kWh})$ & 30 \\
Cost of diesel generator $(\$ / \mathrm{kW})$ & 2257 \\
Cost of PV panels $(\$ / \mathrm{kWh})$ & 368 \\
Cost of wind turbine $(\$ / \mathrm{kWh})$ & 200 \\
Cost of battery banks $(\$)$ & 396 \\
\hline
\end{tabular}


Table 2. Optimal size using M-GWO, GWO and PSO for month of January.

\begin{tabular}{llll}
\hline Components & GWO & PSO & M-GWO \\
\hline $\mathrm{N}_{\mathrm{pv}}$ & 63 & 53 & 60 \\
Peak power of PV panel $(\mathrm{kW})$ & 22,68 & 19,08 & 21,06 \\
$\mathrm{~N}_{\mathrm{WT}}$ & 5 & 6 & 4 \\
Peak power of WT $(\mathrm{kW})$ & 5 & 6 & 4 \\
$\mathrm{~N}_{\mathrm{BB}}$ & 94 & 74 & 93 \\
Capacity of BB $(\mathrm{kWh})$ & 2820 & 2220 & 2790 \\
$\mathrm{~N}_{\mathrm{DG}}$ & 3 & 9 & 2 \\
$\mathrm{~T}_{\mathrm{CC}}(\$)$ & 591768,242 & 591753,321 & 592013,588 \\
$\mathrm{~T}_{\mathrm{RC}}(\$)$ & 123,545 & 222,699 & 272,126 \\
$\mathrm{~T}_{\mathrm{MC}}(\$)$ & 710,609 & 834,27 & 107,486 \\
$\mathrm{~T}_{\mathrm{EC}}(\$)$ & 955,5000 & 1025 & 903.501 \\
$\mathrm{~S}(\$)$ & 0 & 0 & 0 \\
$\mathrm{~T}_{\mathrm{CS}}(\$)$ & 593557,896 & 593835,290 & 593296,701 \\
LPSP & 0,2167 & 0,2283 & 0,2155 \\
$\mathrm{RPS}$ & 0,7833 & 0,7717 & 0,7845 \\
ENS $(\mathrm{kWh})$ & 0,0049 & 0,0054 & 0,0032 \\
\hline
\end{tabular}

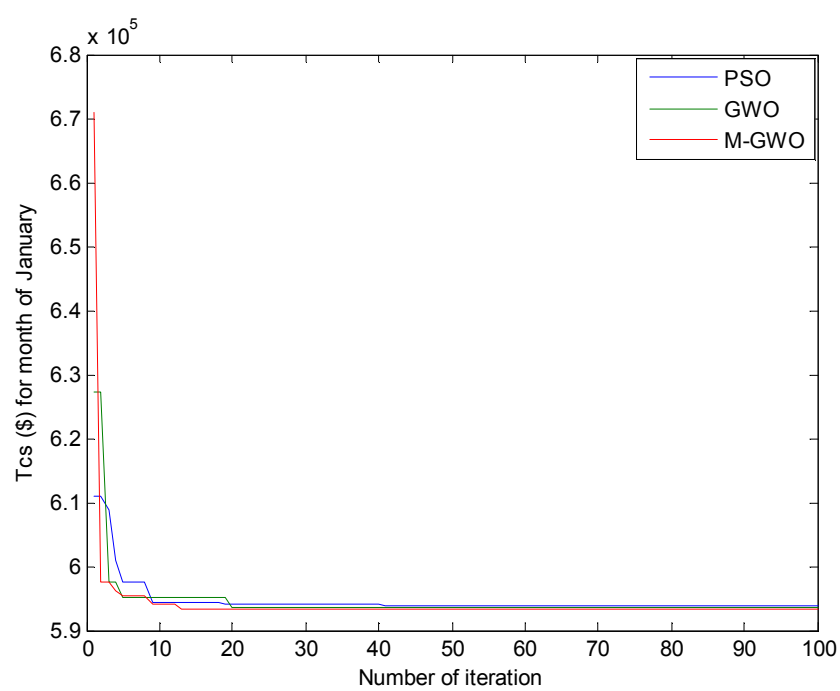

Figure 15. Convergence curve of M-GWO compared to GWO and PSO to find the optimum size for month of January.

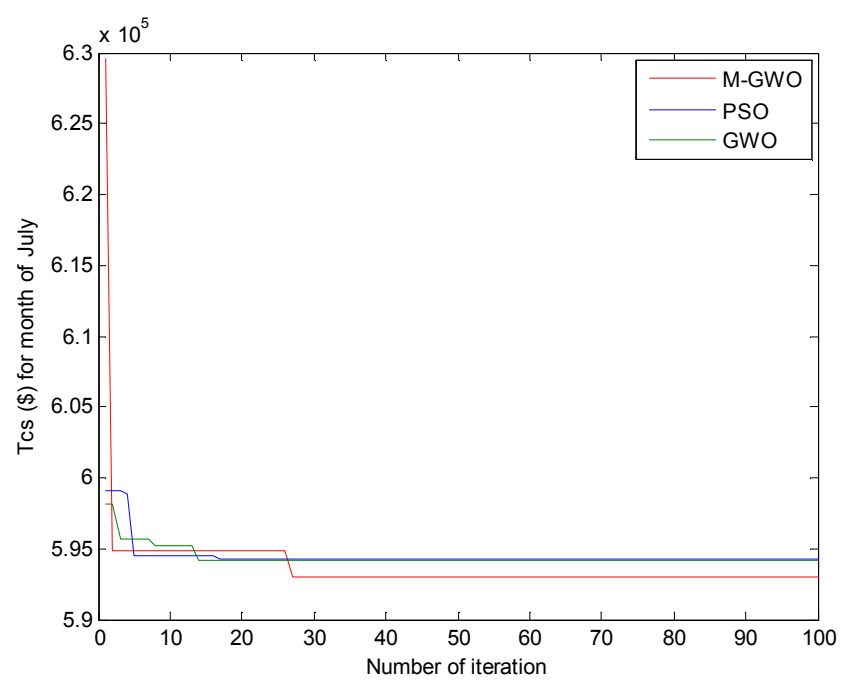

Figure 16. Convergence curve of $M-G W O$ compared to GWO and PSO to find the optimum size for month of July.

Table 3. Optimal size using $M-G W O$, GWO and PSO for month of July.

\begin{tabular}{llll}
\hline Components & GWO & PSO & M-GWO \\
\hline $\mathrm{N}_{\mathrm{pv}}$ & 64 & 56 & 61 \\
Peak power of PV panel $(\mathrm{kW})$ & 23,04 & 20,16 & 21,96 \\
$\mathrm{~N}_{\mathrm{WT}}$ & 7 & 9 & 3 \\
Peak power of WT $(\mathrm{kW})$ & 7 & 9 & 3 \\
$\mathrm{~N}_{\mathrm{BB}}$ & 90 & 96 & 68 \\
Capacity of BB $(\mathrm{kWh})$ & 2700 & 2880 & 2040 \\
$\mathrm{~N}_{\mathrm{DG}}$ & 7 & 3 & 9 \\
$\mathrm{~T}_{\mathrm{CC}}(\$)$ & 591252,459 & 592663,379 & 591932,39 \\
$\mathrm{~T}_{\mathrm{RC}}(\$)$ & 486,888 & 234,345 & 348,727 \\
$\mathrm{~T}_{\mathrm{MC}}(\$)$ & 1206,3 & 718,470 & 110,806 \\
$\mathrm{~T}_{\mathrm{EC}}(\$)$ & 1225 & 675 & 546 \\
$\mathrm{~S}(\$)$ & 0 & 0 & 0 \\
$\mathrm{~T}_{\mathrm{CS}}(\$)$ & 594170,647 & 594291,194 & 592937,923 \\
LPSP & 0,1912 & 0,2169 & 0,1567 \\
$\mathrm{RPS}$ & 0,8088 & 0,7831 & 0,8433 \\
ENS $(\mathrm{kWh})$ & 0,0290 & 0,0301 & 0,0019 \\
\hline
\end{tabular}

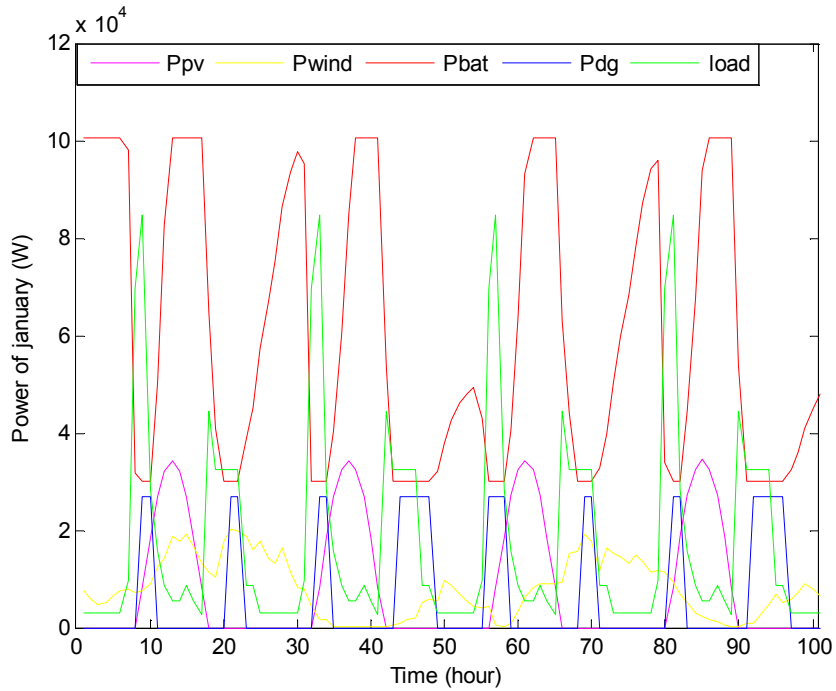

Figure 17. Energy management of hybrid system for month of January.

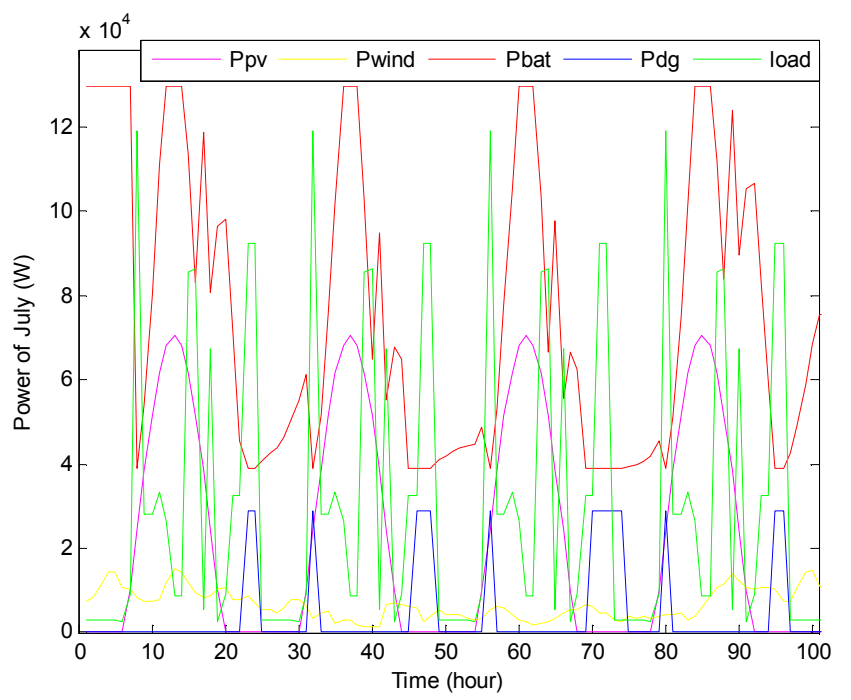

Figure 18. Energy management of hybrid system for month of July.

Figure 17 and Figure 18 depicts the energy balanced in the system for month of January and July respectively. It can be seen the management system of the components with the 
generated energy by each component. It is clear that the system with PV panels only or wind turbines only or diesel generator only is not capable of supplying the load demand. According to the obtained results, the energy difference of generated and demanded energy is managed by battery bank to access the full load supply.

The results of the total power produced by PV panels, $\mathrm{DG}_{\mathrm{s}}$ and battery banks for month of January and July are illustrated in Figure 19 and Figure 20. Figure 21 and Figure 22 shows the total power produced by $\mathrm{WT}_{\mathrm{s}}, \mathrm{DG}_{\mathrm{s}}$ and battery banks for month of January and July respectively. The total power produced byPV panels, $\mathrm{WT}_{\mathrm{s}}$ and battery banks for month of January and July are depicted in Figures 23 and 24.

After simulation of system management we can be tell that the hybrid combination of PV-Wind-DG with battery storage seems to be a motivational techno-economic solution to meet the energy consumption by the load.

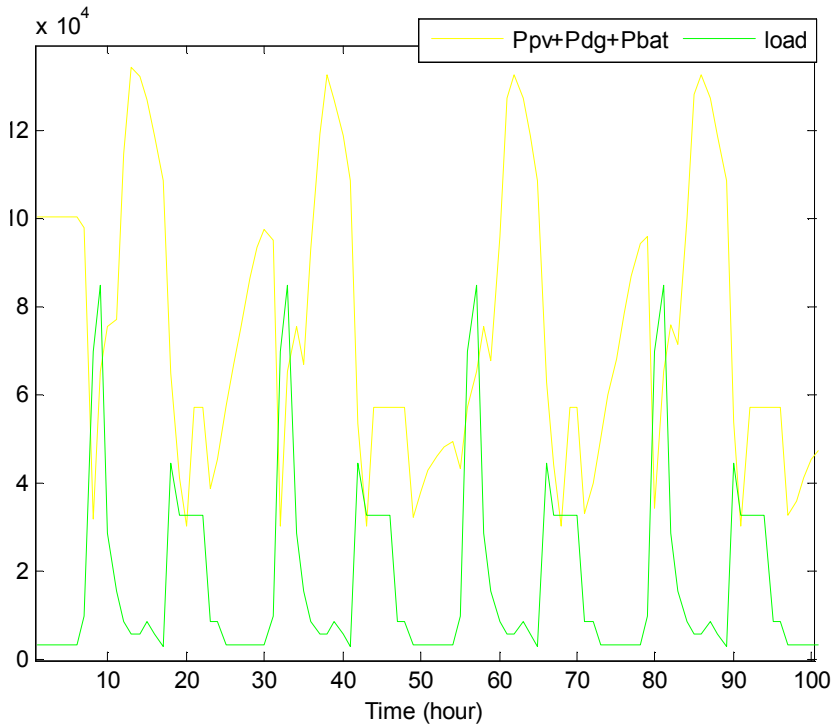

Figure 19. Total power produced by $P V$ panels, $D G_{S}$ and $B B_{S}$ for month of January compared with the load.

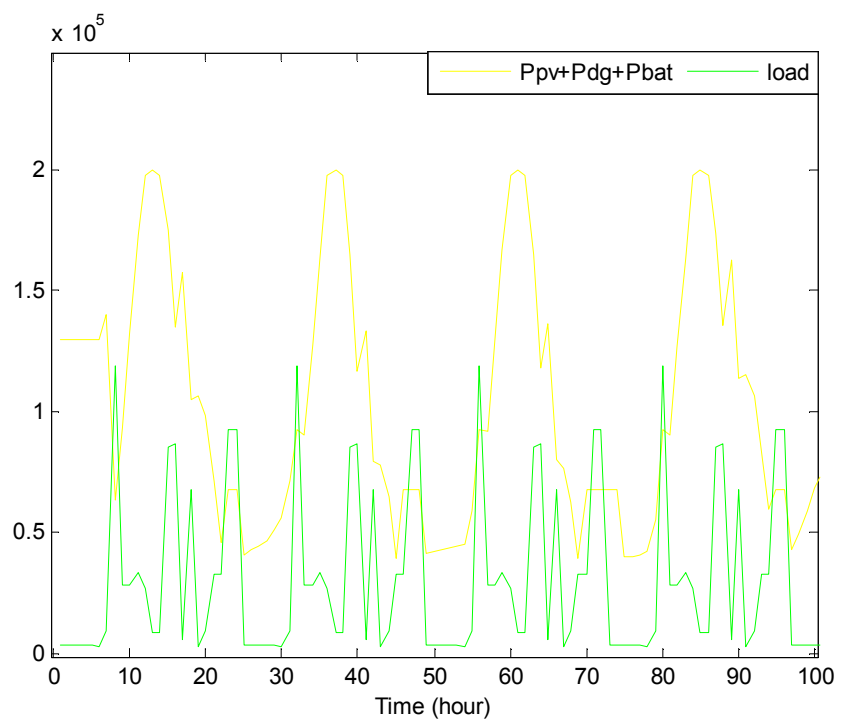

Figure 20. Total power produced by $P V$ panels, $D G_{S}$ and $B B_{S}$ for month of July compared with the load.

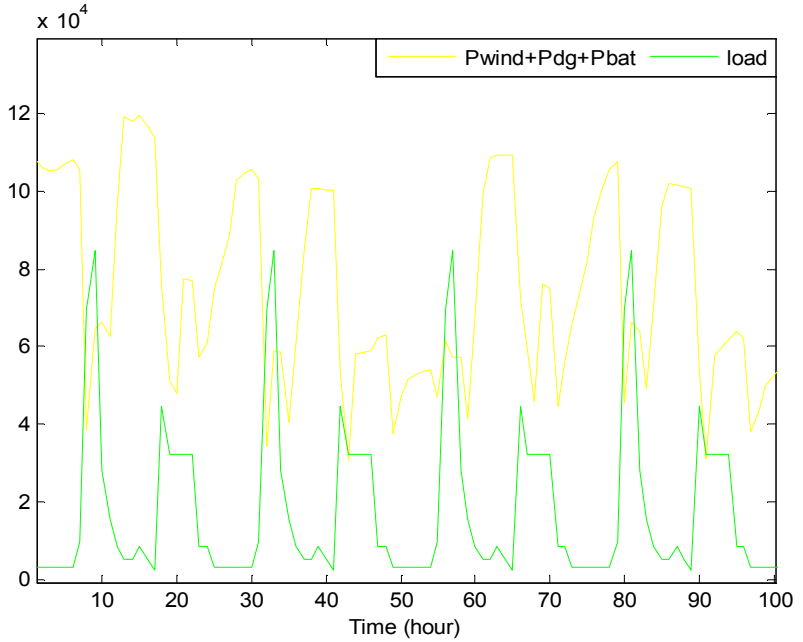

Figure 21. Total power produced by $W T_{S}, D G_{S}$ and $B B_{S}$ for month of January compared with the load.

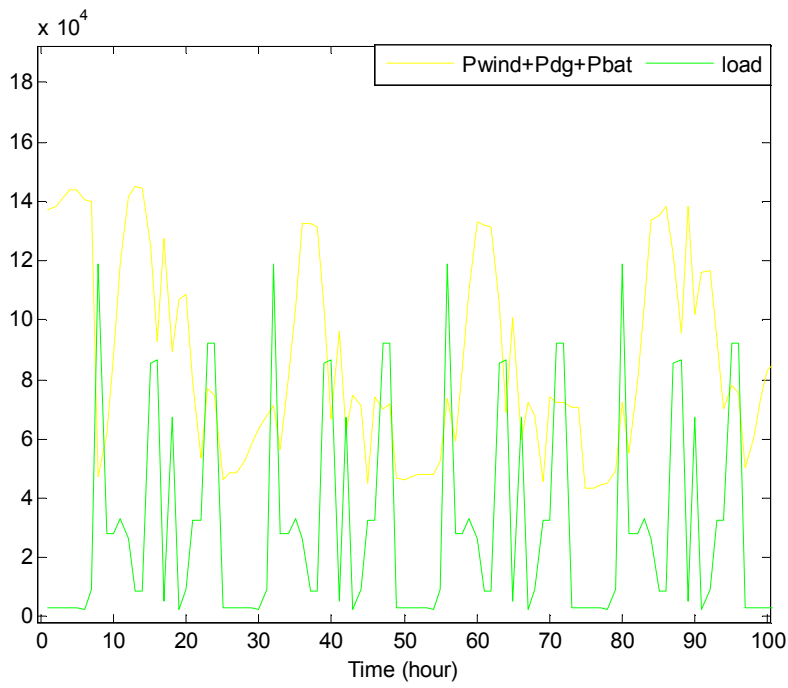

Figure 22. Total power produced by $W T_{S}, D G_{S}$ and $B B_{S}$ for month of July compared with the load.

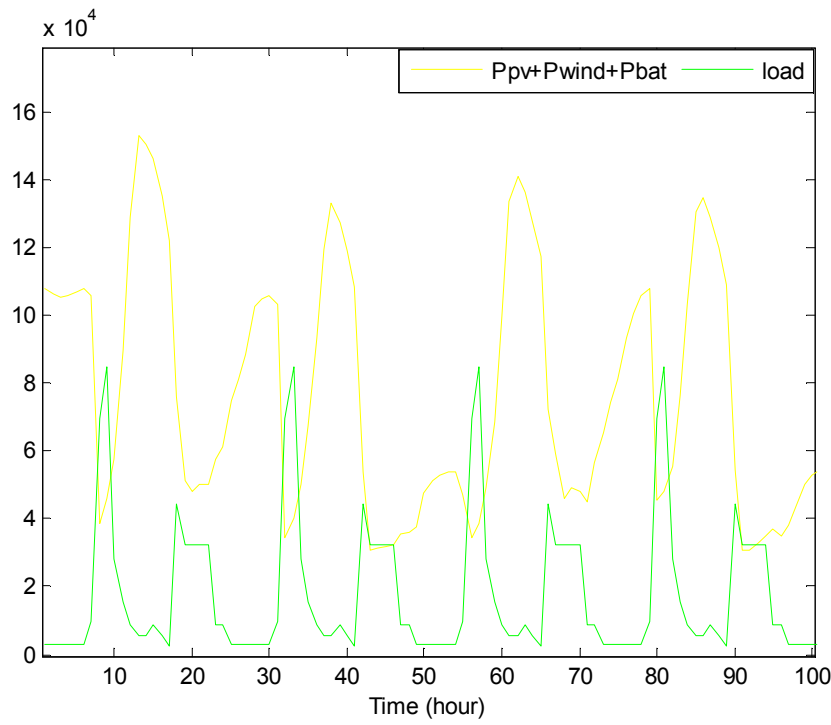

Figure 23. Total power produced by $P V$ panels, $W T_{S}$ and $B B_{S}$ for month of January compared with the load. 


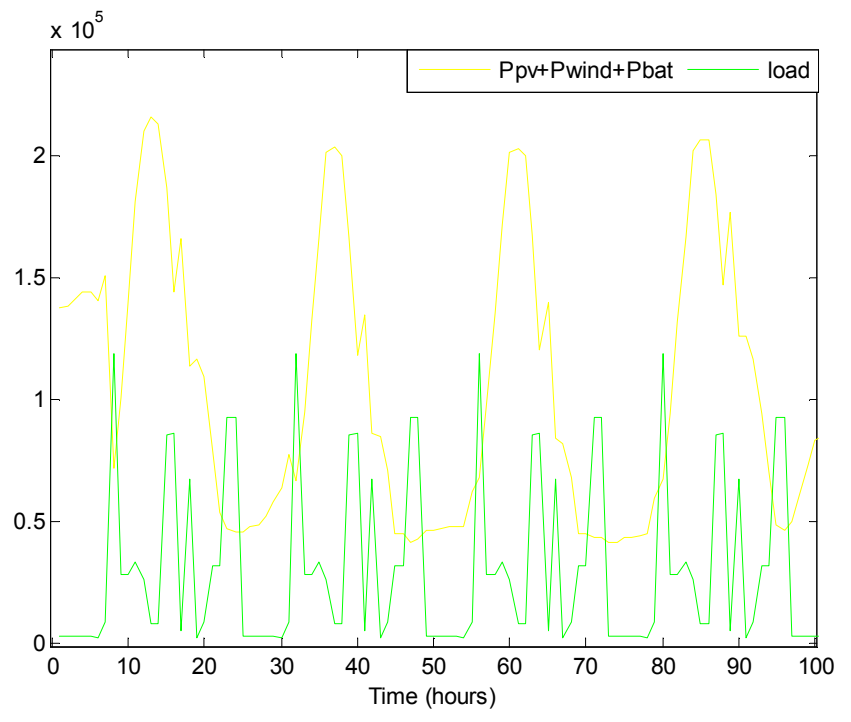

Figure 24. Total power produced by $P V$ panels, $W T_{S}$ and $B B_{S}$ for month of July compared with the load.

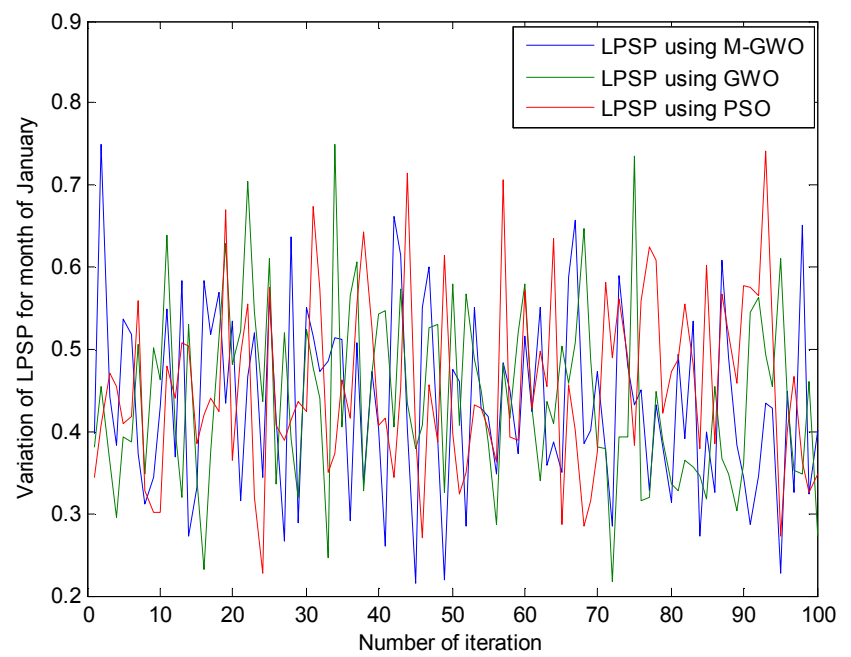

Figure 25. The variation of LPSP for month of January during optimization by M-GWO, GWO and PSO methods.

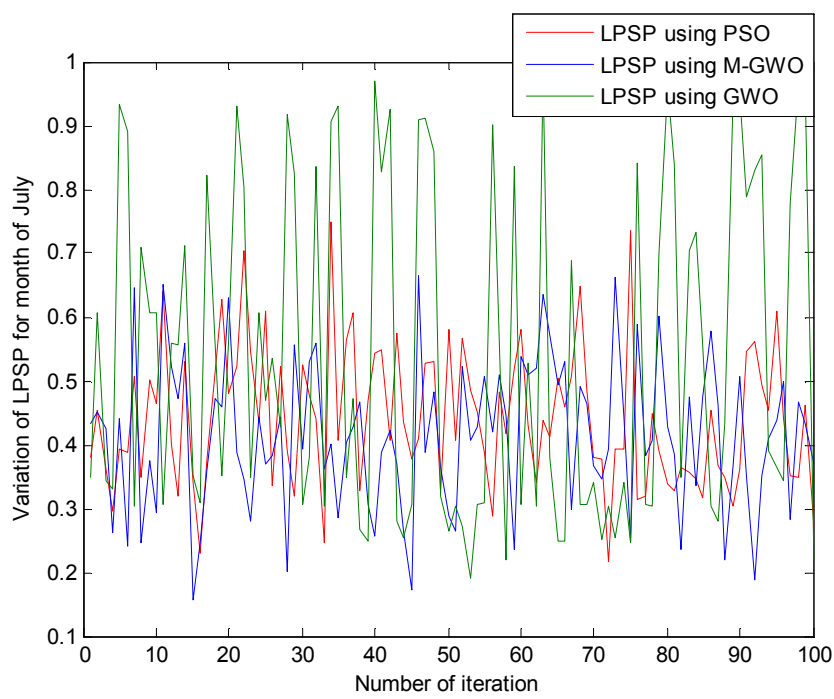

Figure 26. The variation of LPSP for month of July during optimization by $M-G W O, G W O$ and PSO methods.
The variations of LPSP for months of January and July during optimization by M-GWO, GWO and PSO are presented in Figure 25 and Figure 26. It can be seen in these figures that the values of LPSP is almost zero. Which indicates that, the load demand of the system was always satisfied in hybrid wind, solar, diesel and battery system.

Reliability of power supply (RPS) be found from LPSP is illustrated in Figure 27 and Figure 28. From these two concepts it is possible to understand that the system was reliable. Moreover, the energy not supplied (ENS) which is considered when generated power is less than the demanded power was also calculated by the code. The ENS values obtained by optimization with M-GWO is 0,0032 for month of January and 0,0019 for month of July, this means that the load supply reliability is declined. The variations of component availability are ineffective on LPSP, RPS, and ENS. Hence, the system is able to fully meet the load demand.

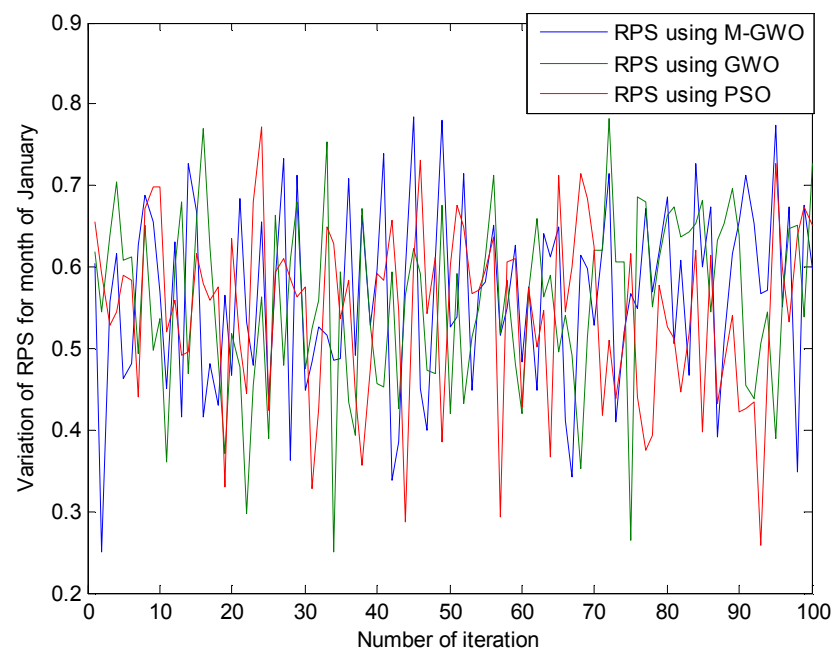

Figure 27. The variation of RPS for month of January during optimization by $M-G W O, G W O$ and PSO methods.

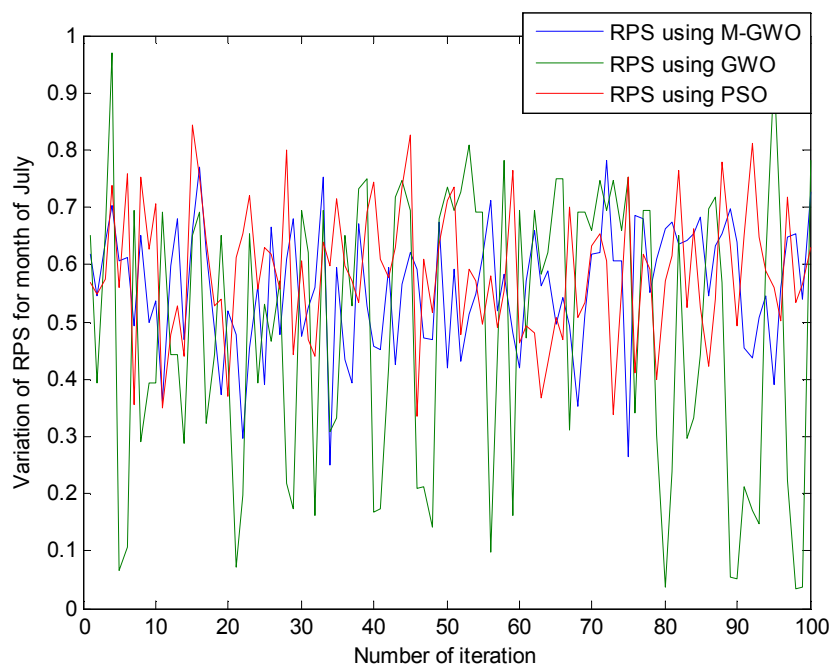

Figure 28. The variation of RPS for month of July during optimization by MGWO, GWO and PSO methods. 


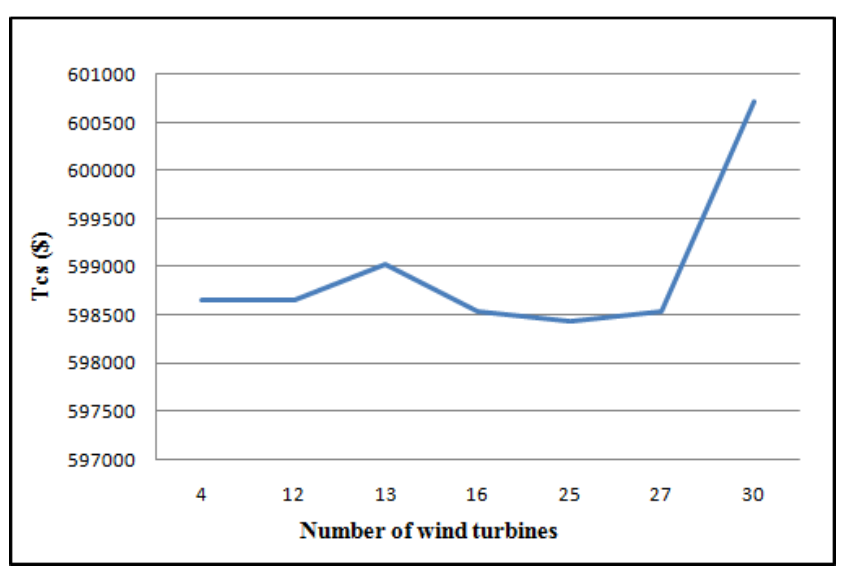

Figure 29. Impact of the number of $W T_{S}$ to the value of $T_{C S}$.

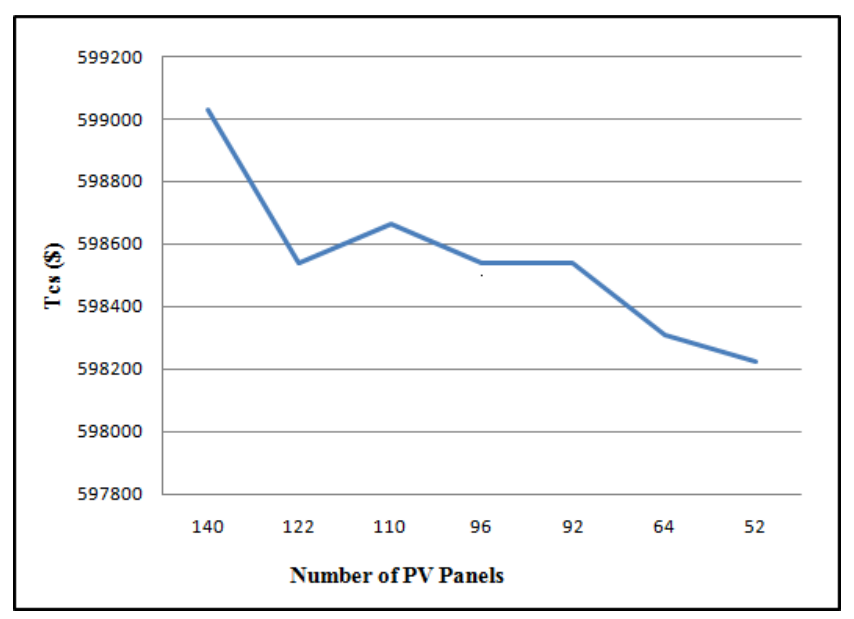

Figure 30. Impact of the number of $P V$ panels to the value of $T_{C S}$.

As shown in Figure 29. Increasing the number of wind turbines will make the total cost going down reach the minimum value. However, after reaching the minimal value, the total cost of the system is increasing due to the increasing of the number of wind turbines. Figure 30 depicts the impact of incorporating the number of PV panels with total cost. The value of $\mathrm{T}_{C S}$ decreases due to decreasing the number of $\mathrm{PV}$ panels. However, the value of $\mathrm{T}_{\mathrm{CS}}$ is raising up after approaching the optimal value. Connecting significant number of PV panels will reduce the cost of $\mathrm{DG}_{\mathrm{s}}$. however, adding more PV panels after approaching the optimal size will increase the total cost of system.

Some sensitivity variables were fed into M-GWO technique to determine theoptimal system combination and commensurate techno-economic analysis for such systems. In conducting the sensitivity analysis in this work, avariation in the solar insolation, fluctuations in system components prices was conducted. After simulation results it can be seen that the amount of energy loss varies as a function of the total emission cost with a stability of the total cost system, so it can be said that the optimal system configuration does not change with increasing or decreasing LPSP and $T_{E C}$. As it is obvious from the result, there is a reduction in the total cost of the HPWDBS since the optimal value decrease.

\section{Conclusion}

This research analyzed the techno-economic feasibility of the hybrid renewable energy systems (PV-wind-DG-BB) to guarantee the energy requirements for the electrification of village in wilaya of Ghardaïafor two months (January present the winter season and July present the summer season) with a daily consumption of up to $453.8 \mathrm{kWh}$ per day for January, and $785,86 \mathrm{kWh}$ per day for July. The combination of PV system and wind turbine are not cost competitive compared to conventional fossil fuel, but could be very good opportunity for isolated place like small village or rural houses. Different conclusionscould be made from this particular analysis. The most economic hybrid renewable energy system to supply the load demand with a Total Cost System $\left(\mathrm{T}_{\mathrm{CS}}\right)$ value equal to 593296,701 \$ with electrical energy obtained from PV panel is $55 \%, 15 \%$ from WT, 28\% from DG and 2\% from BB for January and 592937,923 \$ with electrical energy obtained from PV panels reaches up to $53 \%, 17 \%$ from $\mathrm{WT}_{\mathrm{s}}, 28 \%$ from $\mathrm{DG}_{\mathrm{s}}$ and $2 \%$ from BB for July. The proposed model can be used in feasibility studies and the design of hybrid renewable energy systems. The results showed that reliability model has an important impact on optimal sizing, cost system, and load supply. The M-GWO method has ability to reach global optimum with relatively simple computation requirement. The results prove the competence and superiority of M-GWO compared to GWO and PSO and it has an ability to become an effective tool for solving real word optimization problems. According to this comprehensive study, it can be concluded that the proposed algorithm has significant merits to solving the optimal design problems of hybrid renewable energy systems.

\section{References}

[1] IEA, Global Energy Review, Paris https://www.iea.org/reports/global-energy-review-2020.

[2] Yousefi, A., Eslamloueyan, R., and Kazerooni, N. M. (2017). Optimal conditions in direct dimethyl ether synthesis from syngas utilizing a dual-type fluidized bed reactor. Energy, 125: 275-86.

[3] Khojasteh, D., Khojasteh, D., Kamali, R., Beyene, A., and Iglesias, G. (2017). Assessment of renewable energy resources in Iran, with a focus on wave and tidal energy. Renewable and Sustainable Energy Reviews.

[4] Ahmad, A., Khan, A., Javaid, N., Hussain, H. M., Abdul, W., Almogren, A., and Azim Niaz, I. (2017). An optimized home energy management system with integrated renewable energy and storage resources. Energies, 10 (4), 549.

[5] Hussain, B., Javaid, N., Hasan, Q., Javaid, S., Khan, A., and Malik, S. (2018). An Inventive Method for Eco-Efficient Operation of Home Energy Management Systems. Energies, 11 (11), 3091.

[6] REN21, Renewables Global Status Report (Paris: REN21 Secretariat). (2018), ISBN 978-3-9818911-3-3.

[7] Hubble, A. H., and Ustun, T. S. (2016). The feasibility of microgrid optimization and grid extension. IEEE region 10 conference TENCON, Singapore. 
[8] Owusu, P. A., and Asumadu-Sarkodie, S. A. (2016). review of renewable energy sources, sustainability issues and climate change mitigation. Cogent. Eng, 3, 1167990.

[9] Ramli, M. A., Hiendro, A., and Twaha, S. (2015). Economic analysis of PV/diesel hybrid system with flywheel energy storage. Renewable Energy. 78, 398-405.

[10] Moreira, D., and Pires, J. C. (2016). Atmospheric $\mathrm{CO}_{2}$ capture by algae: Negative carbon dioxide emission path. Bioresour. Technol, 215, 371-379.

[11] Kim, H., Bae, J., Baek, S., Nam, D., Cho, H., and Chang, H. (2017). Comparative analysis between the government micro-grid plan and computer simulation results based on real data: The practical case for a South Korean Island. Sustainability, 9, 197.

[12] Hosseini, H., Farsadi, M., Lak, A., Ghahramani, H., and Razmjooy, N. (2012). A Novel Method Using Imperialist Competitive Algorithm (ICA) for Controlling Pitch Angle in Hybrid Wind and PV Array Energy Production System. International Journal on Technical and Physical Problems of Engineering (IJTPE), 145-152.

[13] Mollahosseini, A., Hosseini, S. A., Jabbari, M., Figoli, A., and Rahimpour, A. (2017). Renewable energy management and market in Iran: A holistic review on current state and future demands. Renewable and Sustainable Energy Reviews, 80, 774-788.

[14] Bhandari, B., Lee, K-T., Lee, G-Y., Cho, Y-M., and Ahn, SH.(2015). Optimization of hybrid renewableenergy power systems: a review. International Journal of Precision Engineering and Manufacturing-Green Technology, Vol. 2, No. 1, pp. 99-112.

[15] Yahiaoui, A., Benmansour, K., and Tadjine, M. (2016). Control, analysis and optimization of hybrid PV-DieselBattery systems for isolated rural city in Algeria. Solar Energy, 137, 1-10.

[16] Lujano-Rojas, J. M., Dufo-Lopez, R., and Bernal Agustın, J. L. (2013). Probabilistic modeling and analysis of stand-alone hybrid power systems. Energy, 63, 19-27.

[17] Maleki, A., and Pourfayaz, F. (2015). Optimal sizing of autonomous hybrid photovoltaic/wind/battery power system with LPSP technology by using evolutionary algorithms. Solar Energy, 115, 471-483.

[18] Hadidian-Moghaddam, M. J., Arabi-Nowdeh, S., and Bigdeli, M. (2016). Optimal sizing of a stand-alone hybrid photovoltaic/wind system using new grey wolf optimizer considering reliability. journal of renewable and sustainable energy, 8, 035903.

[19] Huneke, F., Henkel, J., Gonzalez, J., Alberto, B., and Erdmann, G. (2012). Optimization of hybrid off-grid energy systems by linear programming. Energy, Sustainability and Society, pp. 2-7.

[20] Tom, W., and Theophilus, A. (2019). Optimal and Economic Evaluation of a Stand-alone Microgrid for Electricity and Water Supply for Namibia's Rural Village. American Journal of Energy Engineering, 7 (3): 64-73.

[21] Khan, A., Javaid, N., and Javaid, S. (2018). Optimum unit sizing of stand-alone PV-WT-Battery hybrid system components using Jaya. IEEE 21st International Multi-Topic Conference (INMIC), 1, pp. 1-8.
[22] Wang, X., Palazoglu, A., and El-Farra, N. H. (2015). Operational optimization and demand response of hybrid renewable energy systems. Applied Energy, 143, 324-335.

[23] Ramli, M. A., Bouchekara, H. R. E. H., and Alghamdi, A. S. (2018). Optimal sizing of $\mathrm{PV} /$ wind/diesel hybrid microgrid system using multi-objective self-adaptive differential evolution algorithm. Renewable Energy, 121, 400-411.

[24] Chellali, F. B. M., Recioui, A., Redah Yaiche, M., and Hamid, B. (2014). A hybrid wind/solar/diesel stand-alone system optimization for remote areas in Algeria. Int. J. Renewable Energy Technology, 5 (1), 12-24.

[25] Billinton, R., Zhang, W. (2001), "Cost related reliability evaluation of bulk power system", Electrical Power and Energy Systems, vol. 23, 99-112.

[26] Kaldellis, J. K., Koronakis, P., and Kavadias, K. (2004). Energy balance analysis of standalone photovoltaic system including variable system reliability impact. Renewable Energy, vol. 29, 1161-1180.

[27] Tanrioven, M., and Alam, M. S. (2006). Reliability fuel cell power plants. Renewable Energy vol. 31, pp. 915-933.

[28] Shi, Z., Wang, R., and Zhang, T. (2015). Multi-objective optimal design of hybrid renewable energy systems using preference-inspired co evolutionary approach. Solar Energy, vol. 118 , pp. $96-106$.

[29] Senjyu, T., Hayashi, D., Yona, A., Urasakiand, N., and Funabashi, T. (2007). Optimal configuration of power generating systems in isolated island with renewable energy. Renewable Energy, 32, 1917-1933.

[30] Maleki, A., and Askarzadeh, A. (2014). Comparative study of artificial intelligence techniques for sizing of a hydrogenbased stand-alone photovoltaic/wind hybrid system. Int. J. Hydrog. Energy, 39, 9973-9984.

[31] Skarstein, O., and Uhlen, K. (1989). Design considerations with respect to long-term diesel saving in wind/diesel plants. Wind Energy, 13, 72-87.

[32] Jae-Hoon, C., Myung-Geun, C., and Won-Pyo, H. (2016). Structure Optimization of Stand-Alone Renewable Power Systems Based on Multi Object Function. Energies, 9, 649; doi: $10.3390 /$ en9080649.

[33] Mengjun, M., Rui, W., Yabing, Z., and Tao, Z. (2017). MultiObjective Optimization of Hybrid Renewable Energy System Using an Enhanced Multi-Objective Evolutionary Algorithm. Energies, 10, 674 doi: 10.3390/en10050674.

[34] Elhadidy, M. A., and Shaahid, S. M. (1999). Optimal sizing of battery storage for hybrid (wind+diesel) power systems. Renewable Energy, 18 (1), 77-86.

[35] Kellog, W., Nehrir, M., Venkataramanan, G., and Gerez, V. (1998). Generation Unit Sizing and Cost Analysis for Stand-alone Wind, Phovoltaic, and Hybrid Wind/PV Systems. IEEE Transactions on Energy Conversion, 13 (1), $70-75$.

[36] Borowy, B. S., and Salameh, Z. M. (1996). Methodology for optimally sizing the combination of a battery bank and PV array in a wind/PV hybrid system. IEEE Transactions on Energy Conversion, 11 (2), 367-375. 
[37] Lu, L., Yang, H., and Burnett, J. (2002). Investigation on wind power potential on Hong Kong islands-an analysis of wind power and wind turbine characteristics. Renewable Energy, 27 (1), $1-12$.

[38] Rajkumar, R. K., Ramachandaramurthy, V. K., Yong, B. L., and Chia, D. B. (2011). Techno economical optimization of hybrid pv/wind/battery system using neuro-fuzzy. Energy, Vol. 36 , No. 8 , pp. $5148-5153$.

[39] Yang, H. X., Burnett, L., and Lu, J. (2003). Weather data and probability analysis of hybrid photovoltaic-wind power generation systems in Hong Kong. Renewable Energy, Vol. 28, pp. 1813-1824.

[40] Suryoatmojo, H., Elbaset, A. A., Pamuji, F. A., Riawan, D. C.,
Nursalim., and Abdillah, M. (2014). Optimal Sizing and Control Strategy of Hybrid PV-Diesel-Battery Systems for Isolated Island. ADCONP Hiroshima.

[41] Yang, H., Lu, Wei Zhou, L., and Fang, Z. (2008). Optimal sizing method for stand-alone hybrid solar-wind system with LPSP technology by using genetic algorithm. Solar Energy, 82.

[42] Suryoatmojo, H., Elbaset, A. A., and Hiyama, T. (2009). Economic and reliability evaluation of Wind-Diesel-Battery system for isolated island considering $\mathrm{CO}_{2}$ emission. IEEJ Trans. PE, vol. 129 (8).

[43] Seyedali, M., Seyed Mohammad, M., and Andrew, L.(2014). Grey wolf optimizer. Advances in Engineering software, vol. 69 , pp. $46-61$. 